Fall 10-2-2017

\title{
Field evidence for the influence of weathering on rock erodibility and channel form in bedrock rivers
}

Charles M. Shobe

College of William and Mary

Gregory S. Hancock

College of William and Mary, gshanc@wm.edu

Martha C. Eppes

Eric E. Small

Follow this and additional works at: https://scholarworks.wm.edu/aspubs

\section{Recommended Citation}

Shobe, Charles M.; Hancock, Gregory S.; Eppes, Martha C.; and Small, Eric E., Field evidence for the influence of weathering on rock erodibility and channel form in bedrock rivers (2017). Earth Surface Processes and Landforms, 42(13), 1997-2012.

10.1002/esp.4163

This Article is brought to you for free and open access by the Arts and Sciences at W\&M ScholarWorks. It has been accepted for inclusion in Arts \& Sciences Articles by an authorized administrator of W\&M ScholarWorks. For more information, please contact scholarworks@wm.edu. 


\title{
Field evidence for the influence of weathering on rock erodibility and channel form in bedrock rivers
}

\author{
Charles M. Shobe, ${ }^{1,2}$ (D) Gregory S. Hancock, ${ }^{1 *}$ Martha C. Eppes ${ }^{3}$ and Eric E. Small ${ }^{2}$ \\ ${ }^{1}$ Department of Geology, College of William and Mary, Williamsburg, VA, USA \\ 2 Department of Geological Sciences, University of Colorado, Boulder, CO, USA \\ ${ }^{3}$ Department of Geography and Earth Sciences, University of North Carolina, Charlotte, NC, USA
}

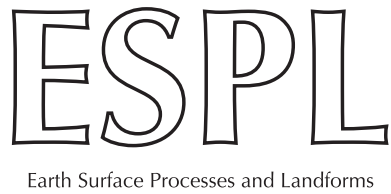

\begin{abstract}
Erosion processes in bedrock-floored rivers shape channel cross-sectional geometry and the broader landscape. However, the influence of weathering on channel slope and geometry is not well understood. Weathering can produce variation in rock erodibility within channel cross-sections. Recent numerical modeling results suggest that weathering may preferentially weaken rock on channel banks relative to the thalweg, strongly influencing channel form. Here, we present the first quantitative field study of differential weathering across channel cross-sections. We hypothesize that average cross-section erosion rate controls the magnitude of this contrast in weathering between the banks and the thalweg. Erosion rate, in turn, is moderated by the extent to which weathering processes increase bedrock erodibility. We test these hypotheses on tributaries to the Potomac River, Virginia, with inferred erosion rates from $\sim 0.1 \mathrm{~m} / \mathrm{kyr}$ to $>0.8 \mathrm{~m} / \mathrm{kyr}$, with higher rates in knickpoints spawned by the migratory Great Falls knickzone. We selected nine channel cross-sections on three tributaries spanning the full range of erosion rates, and at multiple flow heights we measured (1) rock compressive strength using a Schmidt hammer, (2) rock surface roughness using a contour gage combined with automated photograph analysis, and (3) crack density (crack length/area) at three cross-sections on one channel. All cross-sections showed significant $(p<0.01$ for strength, $p<0.05$ for roughness) increases in weathering by at least one metric with height above the thalweg. These results, assuming that the weathered state of rock is a proxy for erodibility, indicate that rock erodibility varies inversely with bedrock inundation frequency. Differences in weathering between the thalweg and the channel margins tend to decrease as inferred erosion rates increase, leading to variations in channel form related to the interplay of weathering and erosion rate. This observation is consistent with numerical modeling that predicts a strong influence of weathering-related erodibility on channel morphology. Copyright @ 2017 John Wiley \& Sons, Ltd.
\end{abstract}

KEYWORDS: bedrock rivers; fluvial geomorphology; weathering; landscape evolution; channel geometry

\section{Introduction}

Rock erosion by rivers is a primary driver of landscape evolution in non-glacial landscapes (Whipple, 2004; Turowski et al., 2008). Downcutting of bedrock rivers sets the boundary conditions for adjacent hillslopes as well as the pace of drainage basin response to baselevel change, climatic changes, tectonics, and other landscape-scale perturbations (Burbank et al., 1996; Whipple and Tucker, 1999; Whipple, 2004; Hobley et al., 2010). Landscape evolution models commonly use stream power and shear stress rules to model rock erosion rates in channels (e.g. Howard and Kerby, 1983; Whipple and Tucker, 1999; Tucker and Whipple, 2002; Lague, 2014). These rules typically incorporate four basic elements: (1) channel gradient; (2) drainage area as a surrogate for discharge; (3) sediment availability for erosion or bed cover; and (4) a constant that implicitly incorporates rock resistance to erosion, referred to here as erodibility. Of these variables, the influence of rock erodibility remains the least well understood. Rock erodibility is dependent in part on inherent rock properties such as tensile strength (e.g. Sklar and Dietrich, 2001) and joint spacing (e.g. Hancock et al., 1998; Whipple et al., 2000). Rock erosion rates are influenced by rock erodibility and rock surface roughness, which are related in part to rock properties and in part to spatial variability in erosional processes (e.g. Hancock et al., 1998; Whipple et al., 2000; Goode and Wohl, 2010; Huda and Small, 2014). Substrate erodibility in bedrock-floored channels is a primary influence on the local gradient along the longitudinal profile (e.g. Han et al., 2014; Duvall et al., 2004) and on channel cross-section geometry (Wohl and Achyuthan, 2002). Rock erodibility may also vary within and across channel cross-sections (Small et al., 2015), and may play a significant role in setting channel geometry and gradient (Hancock et al., 2011).

Physical and chemical weathering processes in rock-floored channels have been suggested as an important mechanism for increasing rock erodibility (e.g. Wohl, 1993; Howard, 1994, 1998; Hancock et al., 1998; Whipple, 2004; Turowski et al., 2009; Hancock et al., 2011; Han et al., 2014; Johnson and Finnegan, 2015; Small et al., 2015; Collins et al., 2016). Weathering is a well-accepted mechanism for reducing rock tensile strength and thereby reducing the critical stress 
necessary to alter rock (e.g. Spears and Taylor, 1972; Gupta and Rao, 2000; Tugrul, 2004; Sousa et al., 2005), which makes rock more susceptible to erosion by abrasion (Sklar and Dietrich, 2001). Weathering may also accelerate block plucking by expanding fractures along which blocks are removed (Hancock et al., 1998; Whipple et al., 2000; Collins et al., 2016). In this article we use the term 'weathering' to mean all in situ physical and chemical weathering processes (for example, oxidation, hydrolysis, microfracture propagation, etc.) that occur at or near the surface of a bedrock outcrop. We use the term 'degree of weathering' to refer to the in situ accumulation of weathering effects (for example, increases in fracture density or porosity, depth of the weathering profile, accumulation of iron oxides or clay minerals, etc.). We use the term 'weathering rate' to refer to the rate at which these changes accumulate.

Field studies completed at the scale of individual river reaches document that rock erodibility within river channels is not constant through time and can vary significantly within the same rock type both along channel profiles and within channel cross-sections (e.g. Montgomery, 2004; Stock et al., 2005; Han et al., 2014; Small et al., 2015; Johnson and Finnegan, 2015; Murphy et al., 2016). Each of these studies suggests that differences in rock residence time within channels and/or differences in rock weathering rates within and along channels cause observed spatiotemporal variation in rock erodibility. However, nearly all published studies that make use of numerical models to simulate longitudinal profile or channel cross-section evolution treat rock erodibility as uniform and constant for a particular rock type in the model (e.g. Stark, 2006; Wobus et al., 2006, 2008; Lague, 2014). To date, there have been limited attempts to incorporate spatial and temporal changes in erodibility into models of bedrock channel evolution.

Variability in rock erodibility may be an important but underappreciated control on the form and gradient of bedrock channels. When numerical models of channel cross-section evolution account for variable rock erodibility, cross-sectional geometry and channel gradient are noticeably different from cases where erodibility is held constant (Hancock et al., 2011). Hancock et al. (2011) hypothesized that the interactions between weathering and erosion within bedrock channels produces variability in rock strength, and hence rock erodibility, across bedrock channels. For instance, exposed rock surfaces along the channel margins may have a longer residence time than rock in the thalweg because stripping of rock by erosion is less frequent on the channel margins. The relative stability of channel margins could result in a more intense degree of bedrock weathering there, as exposure time strongly influences the extent of chemical and physical weathering (e.g. Birkeland, 1999). In this scenario, an increase in rock erodibility on the margins is balanced, however, by lower shear stresses exerted on the margins compared to shear stress in the thalweg. The increase in rock erodibility thus allows the channel margins to erode at long-term rates that are similar to the thalweg, even though the frequency of erosion events and the shear stresses produced by those events are lower than in the thalweg (Hancock et al., 2011).

In the channel cross-section model calculations presented in Hancock et al. (2011), differential degrees of weathering between the thalweg and the margins leads to changes in cross-section geometry. Their model predicts that interaction between the long-term erosion rate and the weathering rate is a potential control on erodibility across bedrock-floored channels. Model experiments with rapid erosion lead to low and nearly uniform rock erodibility, as the rock residence time within the weathering zone is uniformly short. When erosion rates are slow, erodibility is high and nearly uniform, as the rock residence time within the weathering zone is uniformly long. Between the two erosion rate extremes, erodibility varies across the channel, with weathering-induced erodibility increasing with height above the thalweg within the channel cross-section. For all experiments with weathering included, the interaction between erosion and weathering strongly influences channel width/depth $(w / d)$ ratio and channel gradient (Hancock et al., 2011), and represents an additional degree of freedom in bedrock channel evolution. However, field data to evaluate the interaction between rock erosion rates and weathering-driven variability of rock erodibility and the impact of this interaction on channel geometry and gradient is lacking.

In this article, we present the first field-based assessment of hypothesized feedbacks (Hancock et al., 2011; Small et al., 2015) between erosion rate, bedrock weathering, rock erodibility, and channel cross-section form and gradient. We focus on three tributaries to the Potomac River downstream of Great Falls, Virginia, each of which has erosion rates that vary along the channel longitudinal profile. Along these tributaries, typical factors known to influence weathering rates such as precipitation, temperature, vegetation, and lithology (e.g. Birkeland, 1999), are nearly uniform. On each of the three tributaries, we quantify the cross-sectional variability in the degree of weathering for reaches with different erosion rates using several proxies: Schmidt hammer rebound, surface roughness, and crack density measurements. We then address the following questions: (1) how does rock erodibility, as inferred by the weathered state of rock, vary within channel cross-sections? (2) are channel cross-section geometry and gradient affected by the pattern of erodibility across channels? and (3) are the extent and pattern of rock weathering within channel cross-sections related to channel erosion rate? In doing so, we provide the first quantitative evidence supporting the hypothesis that channel cross-section form and gradient are influenced by rock erodibility that varies due to weathering.

\section{Field Setting}

We selected $\sim 0.5-1 \mathrm{~km}$ reaches on three tributaries to the Potomac River (Difficult Run [DR], Scotts Run [SR], and Turkey Run [TR]) located $\sim 3 \mathrm{~km}, \sim 6 \mathrm{~km}$ and $\sim 11 \mathrm{~km}$, respectively, downstream of present-day Great Falls, $\mathrm{a} \sim 20 \mathrm{~m}$ knickpoint on the Potomac (Figures 1 and 2). Criteria for the selection of these study channels included uniformity of lithology and climate, availability of highresolution topographic data, a lack of significant human disturbances, and ease of access. The three tributaries cross similar rock types, primarily the Mather Gorge formation, $\mathrm{a} \sim 600$ Myr old suite of low-grade metasedimentary rocks (Figure 3) (Drake and Froelich, 1997) with some intrusive rocks of the Georgetown Formation. All three tributaries have a knickpoint within $\sim 1 \mathrm{~km}$ upstream of their junction with the Potomac River (Figure 2). A US Geological Survey (USGS) gaging station (USGS 01646000) is located at the upstream end of our sampling locations on Difficult Run, allowing us to calculate stream power along Difficult Run and to estimate flows based on drainage area for the other two tributaries. The climate is characterized by warm summers and relatively mild winters with a mean annual temperature of $14.5^{\circ} \mathrm{C}$ and mean annual precipitation of $\sim 1.1 \mathrm{~m}$ (National Weather Service, 2015, http://www.weather.gov/lwx/dcanme, accessed September 2015). 


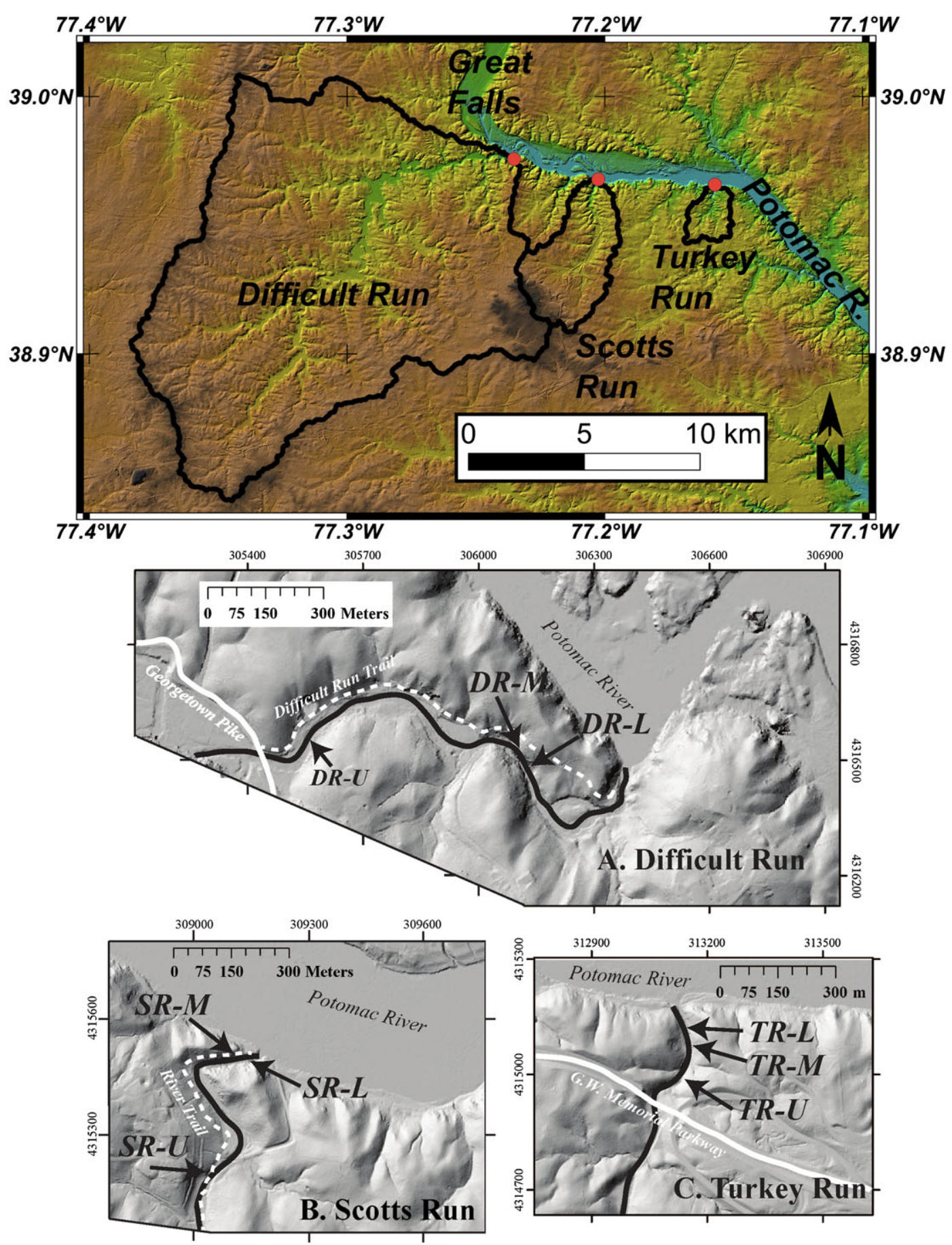

Figure 1. Study locations on tributaries to the Potomac River at Great Falls, Virginia. Study cross-sections are marked on Difficult Run (A), Scotts Run (B), and Turkey Run (C). Upstream cross-sections (DR-U, SR-U, TR-U), middle cross-sections (DR-M, SR-M, TR-M), lower cross-sections (DR-L, SR-L, TR-L). Maximum relief in this landscape is approximately $100 \mathrm{~m}$. [Colour figure can be viewed at wileyonlinelibrary.com]

\section{Methods}

Proxies for rock weathering

We use three proxies to determine the degree of bedrock weathering within and along channels. First, we use uniaxial compressive strength (hereafter compressive strength) measured using a Schmidt hammer, which has been widely used to quantify the overall weathering state of rock surfaces (e.g. Selby, 1980; McCarroll, 1991; Wohl and Achyuthan, 2002; Goudie, 2006; Murphy et al., 2016). Schmidt hammer measurements have been correlated with the weathering characteristics of the upper-most weathering rind of the rock surface and with common measures of rock strength such as Young's Modulus or uniaxial compressive strength (Goudie, 2006). Second, we use measurements of surface roughness, which is recognized to correlate generally with exposure age (e.g. Blackwelder, 1931; McCarroll and Nesje, 1996, Mushkin et al., 2014) due to the development of pitted surfaces and differential relief of grains. There is less work directly correlating surface roughness with weathering processes (e.g. McCarroll, 1991; Gómez-Pujol et al., 2006), but existing studies and the interdependence of exposure age and weathering intensity suggest a positive relationship between surface roughness and weathering extent (Birkeland, 1999). Finally, we measure macro-crack (any linear void $>2 \mathrm{~cm}$ in length) density to quantify the degree of visible physical weathering that is manifest at the rock surface (e.g. Eppes et al., 2010). 

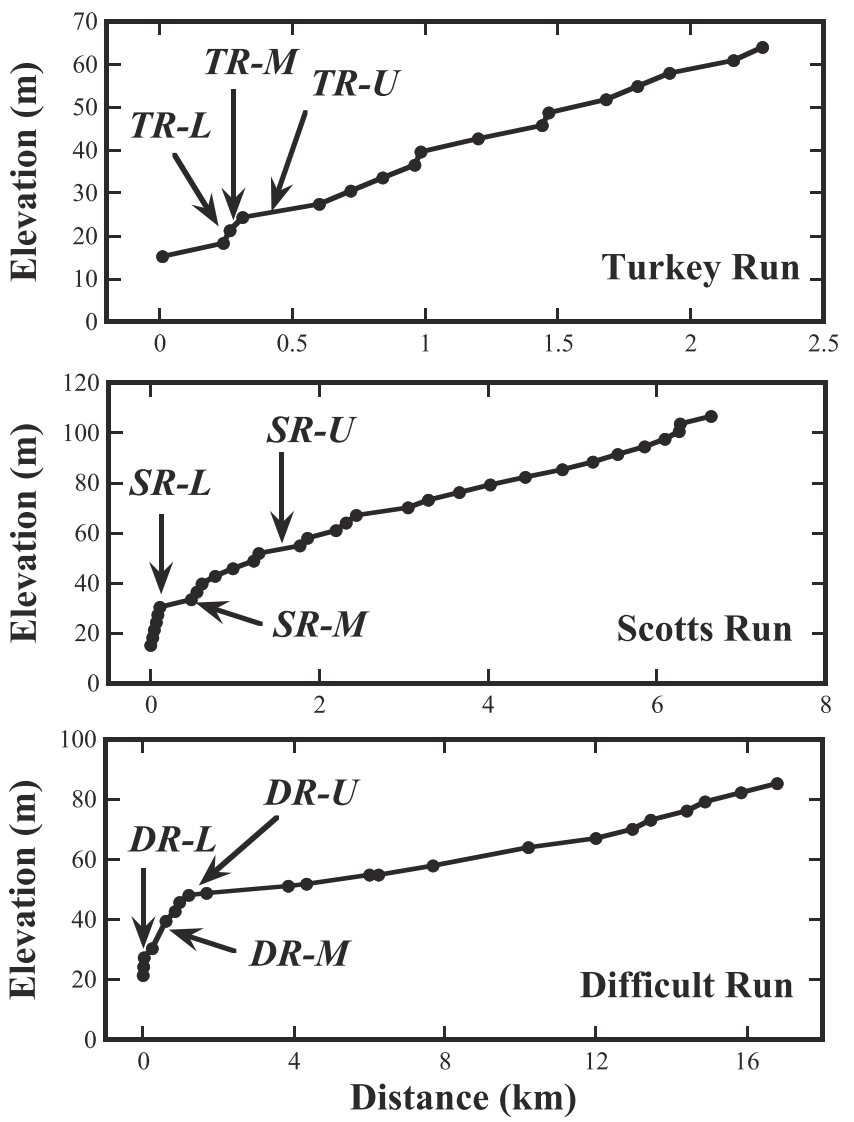

Figure 2. Channel longitudinal profiles and sampling locations. Elevations were obtained from digital elevation models derived from 7.5' USGS topographic maps with 10-foot contour interval.

\section{Sample locations}

The longitudinal profiles, extracted from 10-m digital elevation models, of each of the three tributaries exhibit a knickzone located a short distance upstream of their junction with the Potomac River (Figure 2). We took advantage of the variability in stream power within the knickzones by choosing three measurement sites along each tributary: one at the upstream end of each knickzone (DR-U, SR-U, TR-U), one at the steepest portion of each knickzone, (DR-M, SR-M, TR-M), and one at the downstream base of each knickzone (DR-L, SR-L, TR-L) (Figure 2). Given the proximity of the study sites on each tributary as well as the lack of large tributaries between study sites, we assume discharge and local climate conditions are nearly identical, and therefore that the observed differences in channel width and gradient (as surveyed with a laser total station) between sample sites on each tributary are not related to differences in substrate, flow, or microclimate. The upstream sites are located just downstream of the transition from alluvial reaches to exposed bedrock reaches. These sites may be undergoing the initial response to upstream knickzone propagation (Haviv et al., 2006; Berlin and Anderson, 2009), but are less steep than the lower knickzone sections. The middle and lower cross-sections on Difficult and Scotts Runs are steeper and narrower than the upper cross-sections on each channel, while all three Turkey Run cross-sections have similar channel gradient (Figure 2; Table I).

At each sampling site, we selected a channel cross-section that allowed access to the channel bed and margins. Within each cross-section, at varying heights above the thalweg, we chose locations to measure the three proxies for weathering starting at the baseflow waterline and continuing along the cross-section until we reached heights where bedrock exposure

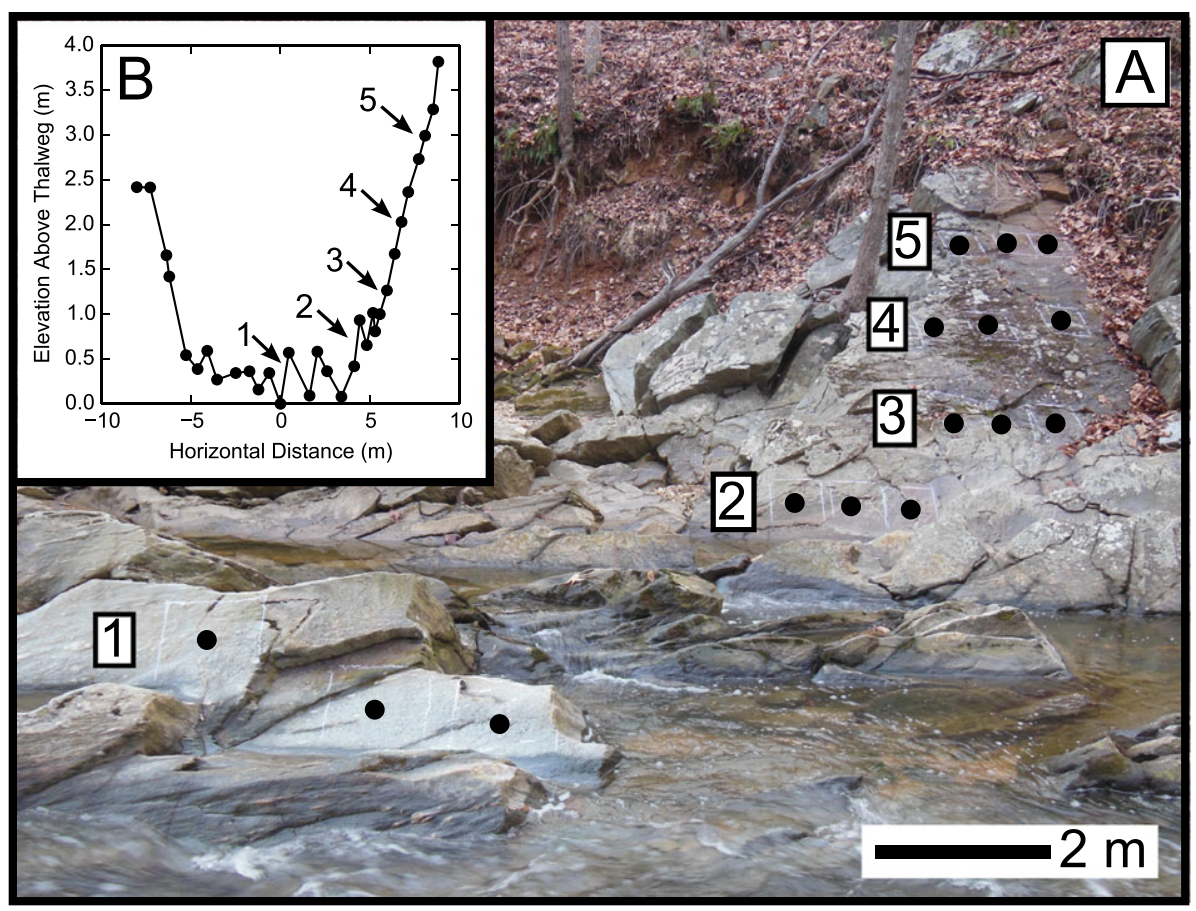

Figure 3. Example of sampled cross-section (Scott Run, site SR-U). Each black dot in (A) marks the middle of the $35 \mathrm{~cm} \times 35 \mathrm{~cm}$ rock surface sampling grid within which 25 Schmidt hammer measurements and two contour gage surface roughness measurements were taken. Each set of three rock surface samples makes up a single measurement location at a single height above the thalweg. (B) Surveyed channel cross-section with sample locations shown in (A). All plots of proxies for weathering incorporate all data from each location (set of three black dots at a single height) into a single data point. [Colour figure can be viewed at wileyonlinelibrary.com] 
Table I. Properties of sampled channel cross-sections

\begin{tabular}{|c|c|c|c|c|c|c|}
\hline Cross-section & Channel slope & $\begin{array}{l}\text { 10-year Stream } \\
\text { power }\left(\mathrm{W} / \mathrm{m}^{2}\right)\end{array}$ & $\begin{array}{l}\text { 50-year Stream } \\
\text { power }\left(\mathrm{W} / \mathrm{m}^{2}\right)\end{array}$ & $\begin{array}{l}\text { 10-year Width/depth } \\
(w / d) \text { ratio }\end{array}$ & $\begin{array}{c}50 \text {-year } w / d \\
\text { ratio }\end{array}$ & $\begin{array}{l}\text { Total Schmidt points } \\
\text { (total roughness profiles) }\end{array}$ \\
\hline \multicolumn{7}{|l|}{ Difficult Run } \\
\hline DR-U & 0.024 & 1100 & 2000 & 16.4 & 13 & $375(30)$ \\
\hline DR-M & 0.062 & 10000 & 16000 & 2 & 2 & $225(18)$ \\
\hline DR-L & 0.026 & 2400 & 3700 & 4.8 & 4.7 & $375(30)$ \\
\hline \multicolumn{7}{|l|}{ Scotts Run } \\
\hline SR-M & 0.075 & 3100 & 5200 & 6.5 & 6.2 & $300(24)$ \\
\hline SR-L & 0.05 & 3000 & 6200 & 4.6 & 3.3 & $375(30)$ \\
\hline \multicolumn{7}{|l|}{ Turkey Run } \\
\hline TR-U & 0.042 & 1400 & 2400 & 6 & 5.2 & $345(30)$ \\
\hline TR-M & 0.044 & 1200 & 2000 & 5.3 & 5.3 & $450(36)$ \\
\hline TR-L & 0.04 & 1800 & 2700 & 3 & 3.1 & $375(30)$ \\
\hline
\end{tabular}

Note: 'total Schmidt points' and 'total roughness profiles' report the number of individual measurements collected in each cross-section. All measurements taken at a given sample location within a cross-section (i.e. a given height above the thalweg) are averaged to give the data as plotted elsewhere in the article (e.g. Figure 5). Channel slopes and $w / d$ ratios were derived from laser surveys.

was limited by regolith (Figure 3). All sample locations were within the active channel. Within each cross-section, three to seven of these measurement locations were chosen, depending on outcrop accessibility. Sampling was conducted on exposed rock outcrops generally exceeding $\sim 10 \mathrm{~m}^{2}$ in area. At each location (a single height above the thalweg consisting of three adjacent rock surfaces), we sampled the three separate rock surfaces in a transect of constant height above the thalweg (Figure 3). The one exception is cross-section TR-U, where one location had only enough space for sampling of two surfaces. Most of the rock faces sampled were striking parallel to the stream flow. In addition to sampling locations within the active channel, we also collected compressive strength and surface roughness data on at least one in situ outcrop located on the adjacent hillslopes and above the maximum flood level ( $\sim 9 \mathrm{~m}$ to $\sim 20 \mathrm{~m}$ above the channel thalweg) on each of the three streams (cross-sections DR-U, DR-L, SR-M, TR-U, and TR-L).

\section{Compressive strength measurements}

We used a Proceq brand Type N SilverSchmidt hammer (Schmidt hammer) to measure the uniaxial compressive strength of the bedrock. The Schmidt hammer measures uniaxial compressive rock strength by recording the rebound velocity of a plunger that strikes the rock surface. Lower rebound velocity indicates lower compressive rock strength, while higher rebound velocity indicates higher compressive strength. The Schmidt hammer uses a proprietary unit of compressive strength, $Q$, which ranges up to $\sim 100$ (Proceq, SilverSchmidt user manual), and with a low detection limit of 10 . For a given rock type, we assume that weathered rock will possess a lower compressive strength, and hence a lower $Q$, than unweathered bedrock (Goudie, 2006; Sumner and Nel, 2002). We do not convert $Q$ to compressive strength, as published conversion equations do not span the entire range of our measurements. Hence, we report $Q$ when providing numerical values, but refer to compressive strength when discussing the implications of the measurements.

Though the Schmidt hammer is susceptible to error from surface roughness, distance from fractures, and moisture, it has been shown to be an effective tool for exploring surface weathering for geomorphic purposes (McCarroll, 1991; Sumner and Nel, 2002; Ericson, 2004; Aydin and Basu, 2005; Goudie, 2006; Niedzielski et al., 2009). Two possible sources of error that are difficult to account for are fractures beneath the rock surface and lichen growing on the rock surface that may dampen the Schmidt hammer impact. Aydin and Basu (2005) report that a rock must be free of fractures up to $6 \mathrm{~cm}$ in depth to accurately measure rock compressive strength with a Schmidt hammer. Here, however, the possible presence of subsurface fractures is not a critical uncertainty because small fractures in the subsurface may be caused or enlarged by weathering, so we assume that fracturing at this scale is expression of weathering that is recorded by the Schmidt hammer. We avoided taking measurements of lichen-covered rock.

The suggested minimum sample size for Schmidt hammer datasets is 15 to 30 measurements on a single bedrock surface (e.g. Niedzielski et al., 2009). At each sample location, we placed a sampling grid (a $35 \mathrm{~cm} \times 35 \mathrm{~cm}$ sampling grid with $100 \sim 2.5 \mathrm{~cm} \times \sim 2.5 \mathrm{~cm}$ square cells) on three adjacent rock surfaces of constant height above the thalweg (Figure 3), and collected 25 Schmidt hammer measurements within each grid at randomly chosen points. At cross-section TR- $U$ where one location had only two available surfaces, we collected 30 measurements from each of the two surfaces. At each sample location, a total of at least 60 Schmidt hammer measurements were collected, for a minimum of 225 measurements in each cross-section (Table I). When collecting data, we avoided locations where the rock was visibly wet, as wet rock has been found to show up to $18 \%$ reductions in Schmidt hammer rebound values compared to the same rock when dry (Sumner and Nel, 2002). Although the sampled surfaces were not smooth, we made sure that the Schmidt hammer plunger tip was striking a flat surface. All Schmidt hammer measurements were taken at least $15 \mathrm{~cm}$ from any significant joint $(>5 \mathrm{~mm}$ width). If a randomly selected Schmidt hammer point fell within $15 \mathrm{~cm}$ of a joint $>5 \mathrm{~mm}$ in width, we did not take a measurement and randomly selected another Schmidt hammer point.

Each day in the field, we tested the Schmidt hammer by collecting 25 measurements from a certified calibration anvil and calculated the average $Q$ and standard deviation for the test. The measured values obtained from the anvil were $77 \pm 3.6$, which compares well to the standard value of the calibration anvil (81), indicating relatively small temporal variation in hammer calibration.

\section{Surface roughness measurements}

To measure rock surface roughness, we adapted the roughness profile procedures of McCarroll and Nesje (1996) using a 15$\mathrm{cm}$ wide Fowler contour gage containing 181 independentlymoving $0.8 \mathrm{~mm}$ diameter pins (Figure 4). Within each grid, 


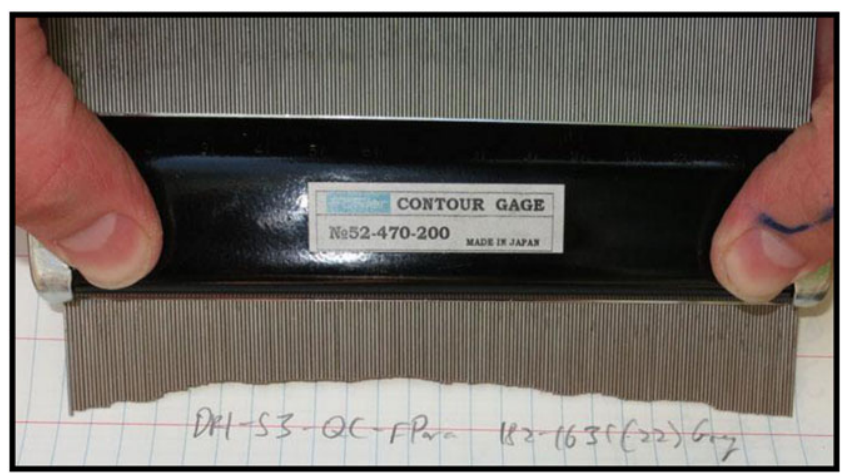

Figure 4. Contour gage photographed after being pressed perpendicularly against the bedrock surface. Photographs were processed using image analysis to determine surface roughness, calculated as the standard deviation of pin heights. [Colour figure can be viewed at wileyonlinelibrary.com]

we collected a set of two surface profiles using the contour gage, one parallel to the stream axis and the other perpendicular to stream axis, following the recommendations of McCarroll (1997). This resulted in a total of six profiles at each height above the thalweg (Table I). Each roughness profile recorded by the contour gage was photographed against a light-colored background, taking care to minimize errors that might be associated with tilting of the background or shadowing of pins. We created an image analysis program in MATLAB based on the Canny edge detection algorithm (Canny, 1986) to extract the roughness profile from the photograph by calculating the standard deviation of height differences between pins. We use the standard deviation of height differences as a proxy for surface roughness following McCarroll and Nesje (1996).

\section{Crack density measurements}

In order to gain a sense of the relative contribution of physical versus chemical weathering to our compressive strength and surface roughness measurements, we also collected crack density data from the highest and lowest measurement sampling locations at each of the three Difficult Run sites. In each sampling location we defined a $1 \mathrm{~m}^{2}$ area around the location of each of the three sample grids. We recorded the length, maximum width, and strike and dip for every crack (defined as a linear void $>2 \mathrm{~cm}$ in length) within that area following the procedures outlined in Aldred et al. (2015). We then summed the total length of all measured cracks for each grid and calculated a crack density as a total crack length per area $\left(\mathrm{cm} / \mathrm{m}^{2}\right)$ for the combined three grids at each elevation above the channel.

\section{Cross-section surveys and recurrence interval calculations}

We surveyed the flow-perpendicular channel cross-section profiles, the sampling locations within cross-sections, and the water surface gradient in each cross-section using a Topcon laser total station (Supporting Information Figure S1). We used the survey data to determine channel cross-sectional area with height above the thalweg and the height above the thalweg of each sampled location. We calculated water-surface slope by measuring water surface elevations above, within and downstream of each sampled cross-section along 50 m total stream length (Table I).
We created a discharge rating curve for each sampled crosssection. We used the channel surveys to obtain the crosssectional area with height above the thalweg at $1 \mathrm{~cm}$ intervals, and estimated the mean flow velocity at each height using the Manning equation. We assumed a Manning's roughness value of $n=0.04$ for all cross-sections and used the surveyed watersurface gradient discussed earlier. Manning's $n=0.04$ is appropriate for steep streams that have little in-channel vegetation but host vegetation high on the banks that may be inundated during high flows (e.g. Chow, 1959). Using the flow regression equations provided in Austin et al. (2011), we calculated the 10-year and 50-year recurrence interval flows $\left(Q_{10}\right.$ and $\left.Q_{50}\right)$ in each sampled cross-section by using drainage area to scale flows from a gaging station on Difficult Run. The discharges estimated from the regression equations were then used in conjunction with the rating curve to approximate the flow depth and width at the 10-year and 50-year flows. We then calculated the unit stream power, $\omega$, for $Q_{10}$ and $Q_{50}$ in each sampled cross-section (Table I).

\section{Results}

For all results reported, we use a significance threshold of $p<0.01$ (99\% confidence) for compressive strength and $p<0.05$ (95\% confidence) for surface roughness due to the lower sample sizes of surface roughness data. Compressive strength decreases with height above the thalweg in all of the sampled channel cross-sections (Figure 5). Using a twosample Welch's $t$-test assuming unequal variance, the means of compressive strength at the lowest and highest height in each cross-section are statistically different $(p<0.01)$ in eight of nine cross-sections (Table II). However, the scatter in the data is enough that Spearman correlation tests do not show significant correlations between compressive strength and height above the thalweg (Table II), and the linear regressions shown in Figure 5 do not show significant trends. The slope of the linear regression between compressive strength and height above the thalweg varies in each crosssection, but the greatest change in compressive strength with height is observed consistently within the upstream crosssections (DR-U, SR-U, and TR-U) and the smallest change is observed consistently in the middle cross-sections (DR-M, SR-M, TR-M) of the three streams (Figure 5). A linear fit of compressive strength with height in each cross-section shows a similar $y$-intercept (e.g. rock strength at the base of the channel, Table II, Figure 5) for each channel, suggesting exhumation in the thalweg of rock of similar initial strength along each channel.

We observe an overall increase of surface roughness with height above the thalweg in seven of the sampled channel cross-sections (Figure 6). The mean surface roughness at the lowest and highest height in each cross-section are statistically different $(p<0.05)$ in six of the nine cross-sections (Table II), again using a two-sample Welch's t-test assuming unequal variance. Taking 0.05 as our significance threshold, Spearman correlation tests indicate that the relationship between height above the thalweg and surface roughness is significant in two cross-sections (Table II), and that the linear regression in DR-L is the only statistically significant linear relationship (Figure 6). The slope of the relationship between surface roughness and height above the thalweg varies in each cross-section, but the greatest change in roughness with height is observed within the DR- $U$ and TR- $U$ cross-sections as well as cross-section DR$\mathrm{L}$, and smaller changes are observed consistently in the middle cross-sections (DR-M, SR-M, TR-M) of the three streams (Figure 6). As with the compressive strength data, a linear fit of 

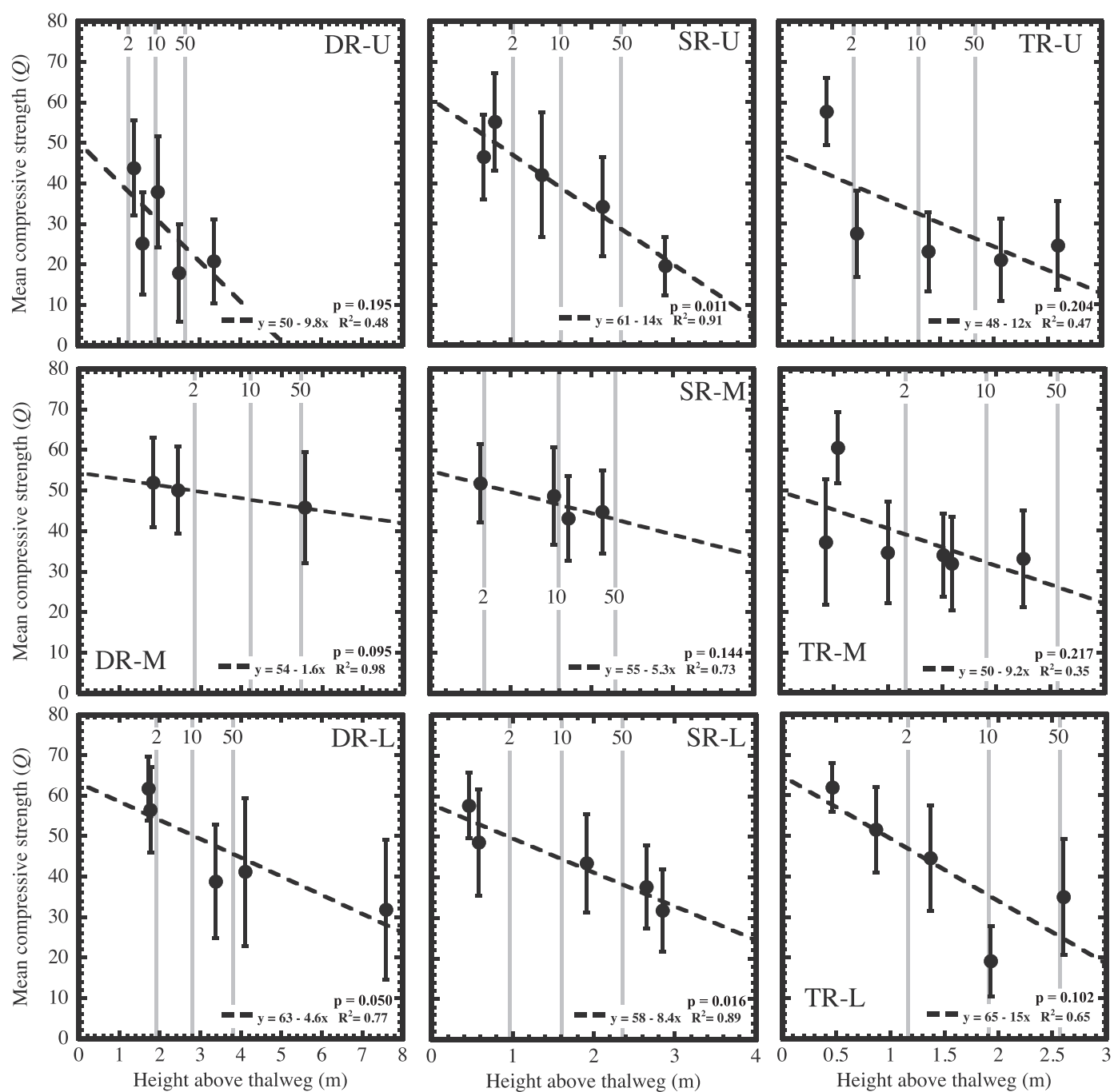

Figure 5. Mean compressive strength plotted against height above the thalweg within each cross-section. Error bars represent one standard deviation. DR, Difficult Run; SR, Scotts Run; TR, Turkey Run. Gray bars show the estimated water level height above the thalweg for the 2, 10, and 50-year recurrence flows at each cross-section. The $p$-values are derived from linear regression analysis. Spearman correlation coefficients and $p$-values are found in Table II. In all nine cross-sections, compressive strength decreases with height above the thalweg.

roughness with height in each cross-section yields a similar $y$ intercept (e.g. roughness at the base of the channel) for all nine cross-sections $(0.16 \pm 0.037 \mathrm{~mm})$.

To more fully investigate the statistical significance of our results, and to compare compressive strength and surface roughness results between cross-sections and channels, we normalized height above the thalweg between cross-sections by converting each measurement height to a recurrence interval using the methods described earlier (see section entitled 'Cross-section surveys and recurrence interval calculations'). When normalized by recurrence interval, both compressive strength and surface roughness data show clear evidence of higher rock erodibility at higher recurrence intervals (Figure 7). Compressive strength declines with increasing recurrence interval, and surface roughness increases with increasing recurrence interval. Spearman rank correlations show that both trends are statistically significant $(p<0.0001)$. While the relatively sparse data within any given cross-section does not always show a statistically significant relationship between height above the thalweg and our erodibility proxies, Figure 7 shows that the trends for compressive strength and surface roughness are significant to a high degree of confidence with all data combined.

Crack density increases with height above the thalweg in all three of the Difficult Run channel cross-sections (Figure 8). The slope of the relationship between crack density and height above the thalweg is greatest in the DR-L and DR- $U$ crosssections, while the DR-M slope is roughly a third of DR-L and DR-U (Table II, Figure 8). As observed in the compressive strength and roughness data, the $y$-intercept of the relationship between crack density and height above the thalweg is similar for all three of the cross-sections on Difficult Run (Figure 8).

The three measured weathering proxies co-vary in systematic ways. Mean compressive strength and mean surface roughness are negatively correlated $\left(R^{2}=0.70,0.42\right.$, and 0.59 in Difficult Run, Scotts Run, and Turkey Run, respectively; Figure 9), consistent with our assumption that rock strength decreases and surface roughness increases as the extent of weathering increases. All three correlations are statistically significant $(p<0.0001, p=0.009$, and $p<0.0001$, respectively). We observe a weak correlation between crack density and mean compressive strength $\left(R^{2}=0.37\right.$ and $\left.p=0.145\right)$, and a strong and significant correlation between crack density and mean surface roughness $\left(R^{2}=0.79\right.$ and $\left.p=0.008\right)$ (Figure 10). This suggests that roughly $40 \%$ of the variance in compressive strength and $80 \%$ of the variance in surface roughness can be explained by the density of visible macrofractures. In general, these correlations are expected between all three metrics. For example, higher crack density leads to erosion of small pieces of rock (and potential preferable detachment of some minerals over others), which increases surface roughness. Laboratory experiments show linear relationships between rock porosity 


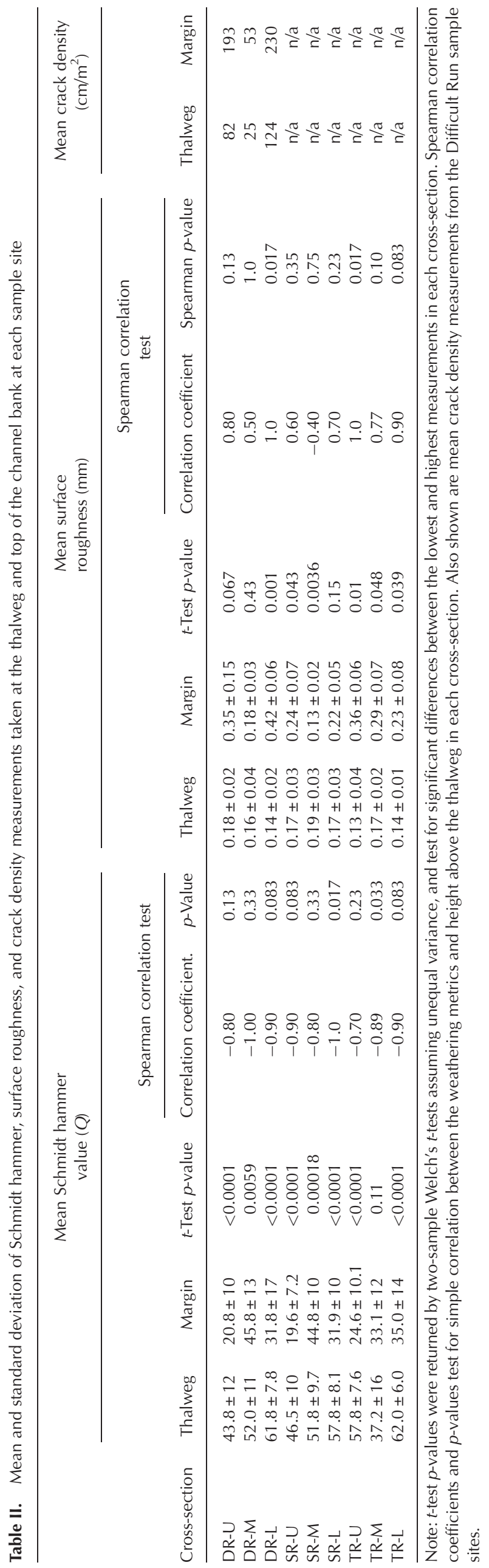



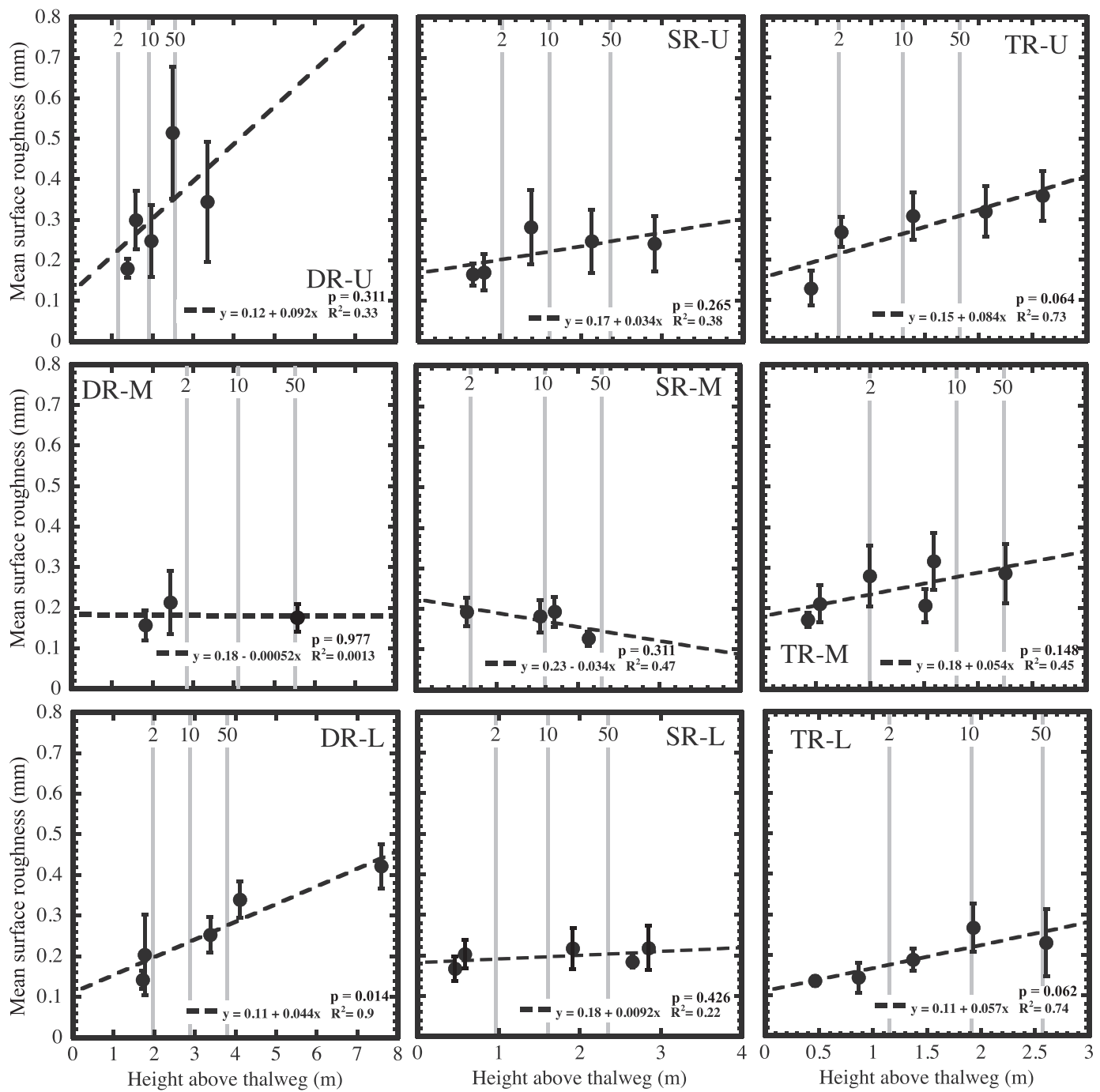

Figure 6. Mean surface roughness plotted against height above the thalweg within each cross-section. Error bars represent one standard deviation. DR, Difficult Run; SR, Scotts Run; TR, Turkey Run. Gray bars show the estimated water level height above the thalweg for the 2, 10, and 50-year flows at each cross-section. The $p$-values are derived from linear regression analysis. Spearman correlation coefficients and $p$-values are found in Table II. In seven of nine cross-sections, surface roughness increases with height above the thalweg.

and compressive strength (Aydin and Basu, 2005). The comparisons with crack density are, to our knowledge, the first data of their kind. They demonstrate that a large portion of the variance in channel bedrock erodibility, as measured by the Schmidt hammer, is attributable to mechanical weathering. The remaining variance may be related to either chemical weathering or to mechanical weathering manifested at smaller scales than the $>2 \mathrm{~cm}$ long cracks we measured.

The compressive strength and surface roughness values measured on rock outcrops on the hillslopes above crosssections DR-U, DR-L, SR-M, TR- $U$, and TR-L indicate much more weathered rock than found near the thalweg. Together, these above-channel outcrops exhibit an average compressive strength of $25 \pm 12 \quad Q$ and average roughness of $0.30 \pm 0.09 \mathrm{~mm}$. The highest sample heights in DR-U, DR-L, and TR-U had compressive strengths that are statistically indistinguishable from the values collected from these nearby outcrops ( $p=0.45$ for DR-U, $p=0.36$ for DR-L, and $p=0.06$ for TR-U). In contrast, the highest sampled height in crosssections SR-M and TR-L have greater mean compressive strength than and are statistically distinct $(p<0.01)$ from the hillslope outcrop compressive strength values.

The width and $w / d$ ratio of channel cross-sections change noticeably as erosion rates (as inferred by stream power) change at our field sites (Figure 11). While we do not have data from enough cross-sections to extract statistically significant relationships between $w / d$ and stream power, we can make some qualitative observations from our sites. Channel width and $w / d$ ratios are lower at higher unit stream power (Figure 11). The cross-section with the lowest stream power (site SR-U) has a $w / d$ ratio of $\sim 12$ at the 50-year flood height, while the cross-section with the highest stream power (site DR-M) has a $w / d$ ratio of $\sim 1.9$ at the 50-year flood height. Direct comparison between $w / d$ ratio and variability in rock erodibility is not straightforward because such comparisons do not incorporate channel gradient, an additional degree of freedom for channel adjustment. However, unit stream power incorporates both channel geometry and gradient, and is therefore more effective for comparing against variability in rock erodibility. For each cross-section, we compare the estimated 10-year recurrence stream power to three measures of cross-sectional variability in erodibility: standard deviation of compressive strength, the rate of change in compressive strength with height between the lowest and highest measurement, and the rate of change in surface roughness with height (Figure 12). Gradients in compressive strength and surface roughness are derived from the linear regressions in Figures 5 and 6 , respectively. The standard deviation of all compressive strength measurements collected in each crosssection ( $\geq 225$ individual values in each) declines with 


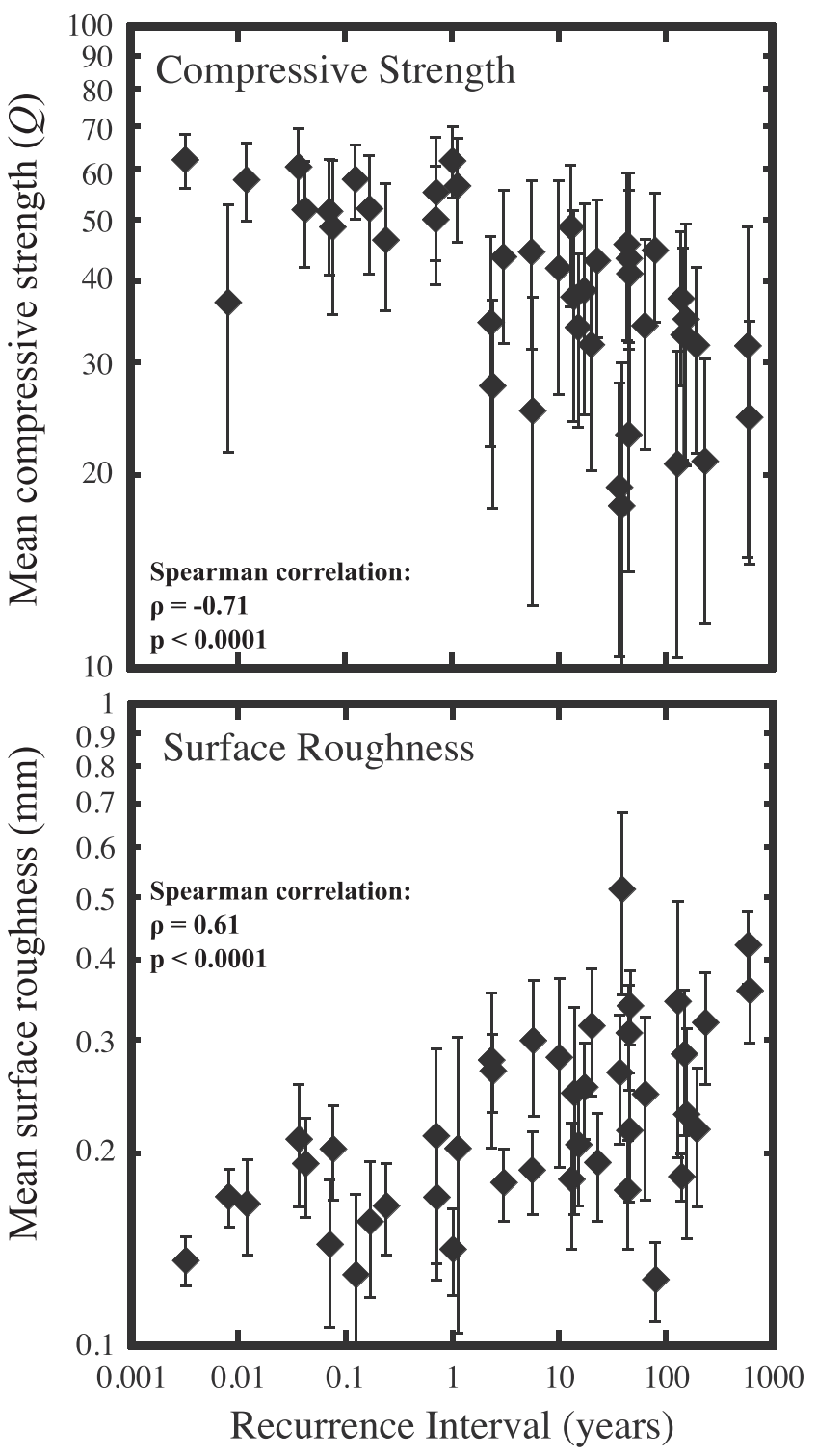

Figure 7. Compressive strength (top) and surface roughness (bottom) data for all measurement heights in all cross-sections. Each measurement height was converted to a flow recurrence interval as described in the text. Lower recurrence intervals are near the thalweg and higher recurrence intervals are higher on the channel banks. Error bars represent one standard deviation. The decrease in compressive strength and increase in surface roughness with increasing recurrence interval are both statistically significant $(p<0.0001)$ using Spearman rank correlation tests, with $\rho$ being the correlation coefficient.

increasing 10-year recurrence unit stream power in Difficult Run and Scotts Run (Figure 12A). The gradients of compressive strength and surface roughness in those channels also decline with increasing 10-year stream power (Figures 12B and 12C). In other words, the difference between values near the thalweg and at the top of the banks is low at high stream power. In Turkey Run, low variability in stream power between crosssections (Figure 12) makes interpretation of weathering variability challenging.

\section{Discussion}

Inundation frequency, weathering, and erodibility

Our dataset of weathering proxies suggests that rock erodibility varies across bedrock-floored channels. Our data reveals a pattern of increasing erodibility with greater height above the

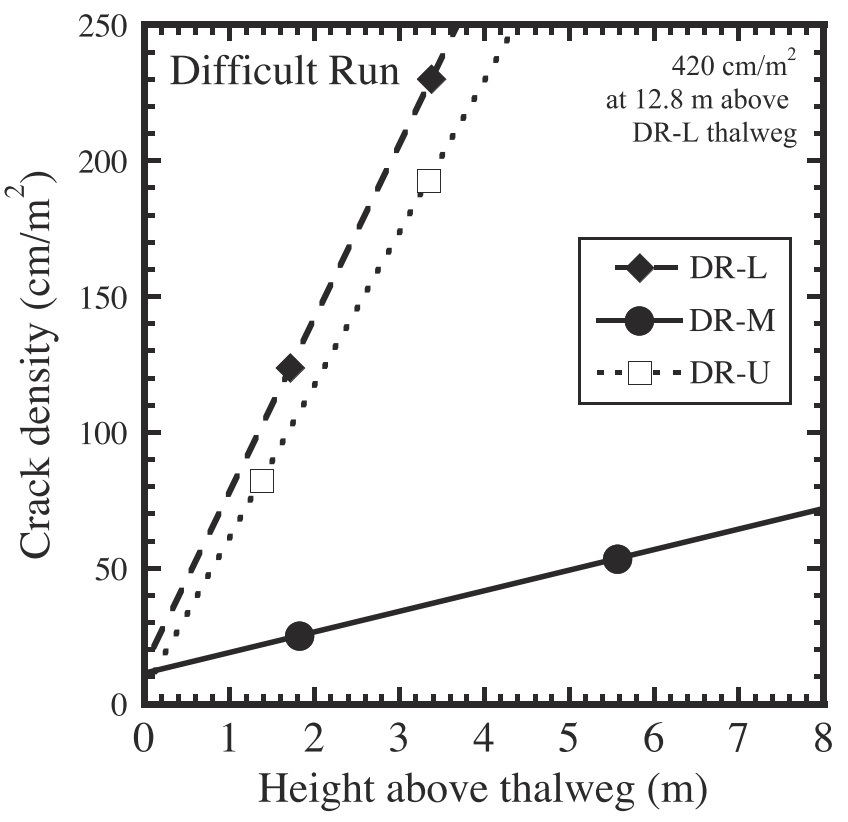

Figure 8. Comparison of crack density with height above the thalweg on Difficult Run (DR). Text in upper right corner reports the crack density measured at an outcrop on the adjacent hillslope. Though our data is limited, we see an increase in crack density with height above the thalweg in all three cross-sections (DR-U, DR-M, DR-L).

thalweg and greater recurrence interval in the cross-sections (Figures 5-7). This trend was observed in one or more weathering proxies at all nine sites, even though the sampled cross-sections were located on three separate streams that differ in watershed drainage area, bank aspect, localized lithologic characteristics, and joint spacing. Measured differences in rock compressive strength within each cross-section are substantial. At the greatest heights within cross-sections, average compressive strength values were as low as $\sim 20 Q$, while values in the thalweg were as high as $\sim 60 Q$ (Figure 5, Table II). This difference can be roughly translated to a nearly nine-fold variation in rock compressive strength (Proceq, SilverSchmidt user manual). Combined compressive strength measurements from all cross-sections show a statistically significant decline with increasing recurrence interval (Figure 7). Although not as definitive as the compressive strength data, the surface roughness and crack density datasets support increasing degree of weathering with height in the channel cross-sections. We observe statistically significant increases in surface roughness between the lowest and highest sampling heights in six of the nine measured cross-sections, as well as a statistically significant increase in roughness with increasing recurrence interval for the entire dataset (Figure 7). Crack density generally increases with height above the thalweg in the three measured cross-sections (Figure 8). The highly significant differences between measurements made at the lowest and highest sampling heights in each cross-section (i.e. between greatest and lowest inundation frequency) combined with a large sample size suggest that these results are robust and are not due to sampling error introduced by our measurement strategy.

We view rock weathering as the only reasonable mechanism available to produce the spatial variability in rock strength, surface roughness, and crack density within these crosssections. Our metrics for weathering largely reflect the effects of physical weathering, in contrast to the chemical weathering mechanisms proposed by Murphy et al. (2016). Measured macrocrack (cracks $>2 \mathrm{~cm}$ length) density accounts for $\sim 40 \%$ of the variance in compressive strength and $\sim 80 \%$ of the variance of the surface roughness data (Figure 10). In addition, 

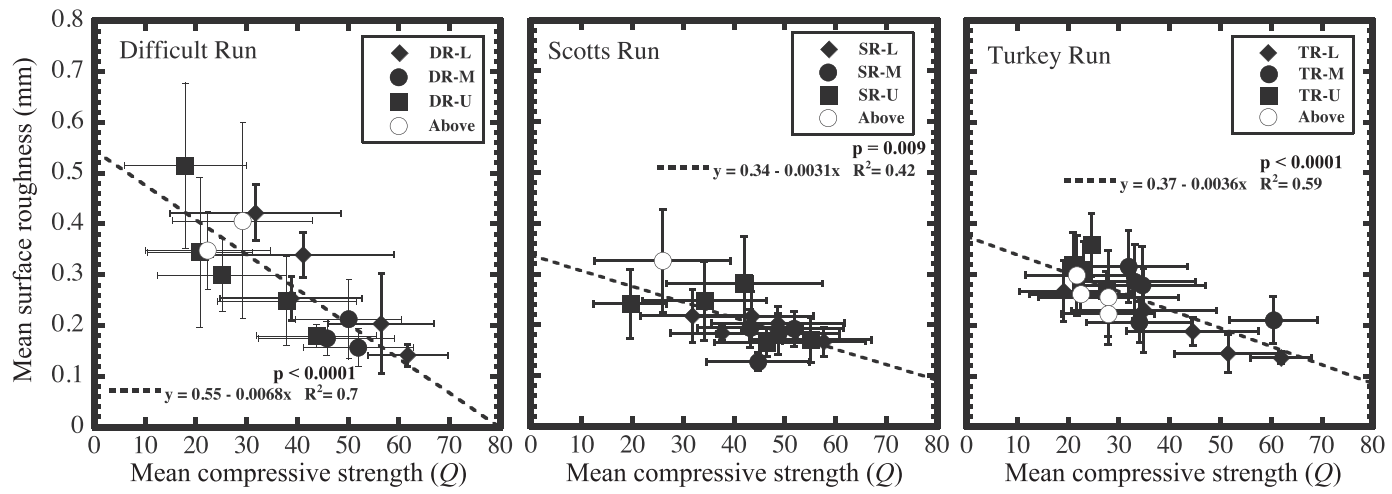

Figure 9. Comparison of surface roughness to compressive strength measurements. Horizontal error bars represent the standard deviation of the $\sim 75$ Schmidt hammer measurements comprising each data point, and vertical error bars represent the standard deviation of the six roughness profiles comprising each data point. Compressive strength and roughness are significantly negatively correlated in each tributary $(p<0.0001, p=0.009$, and $p<0.0001$ for Difficult Run, Scotts Run, and Turkey Run, respectively).
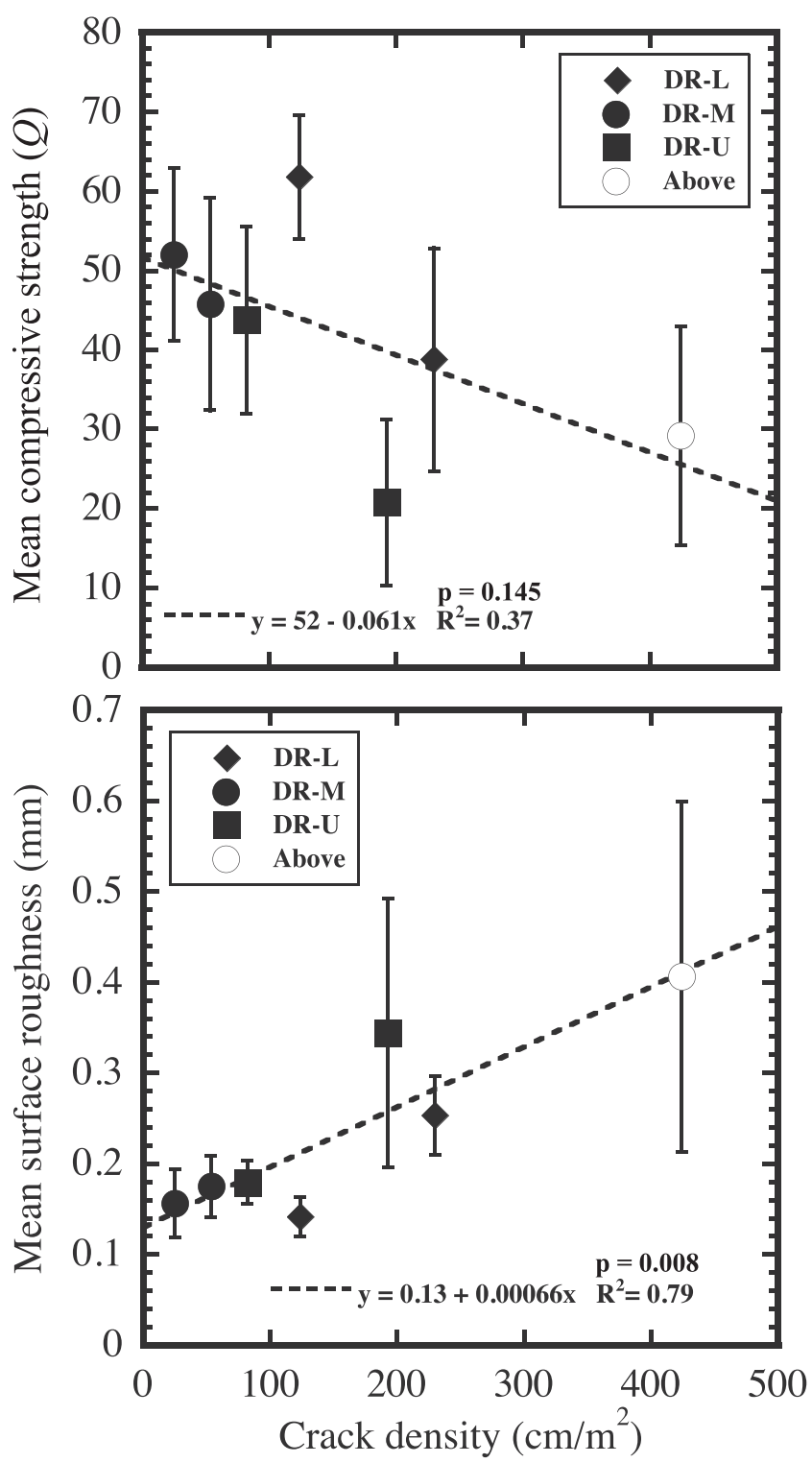

Figure 10. Comparison between crack density and mean rock compressive strength (top) and crack density and mean surface roughness (bottom). In general, compressive strength decreases and surface roughness increases as crack density increases. Error bars represent one standard deviation. We find a significant linear relationship between crack density and surface roughness $(p=0.008)$, but not for crack density and compressive strength $(p=0.145)$.

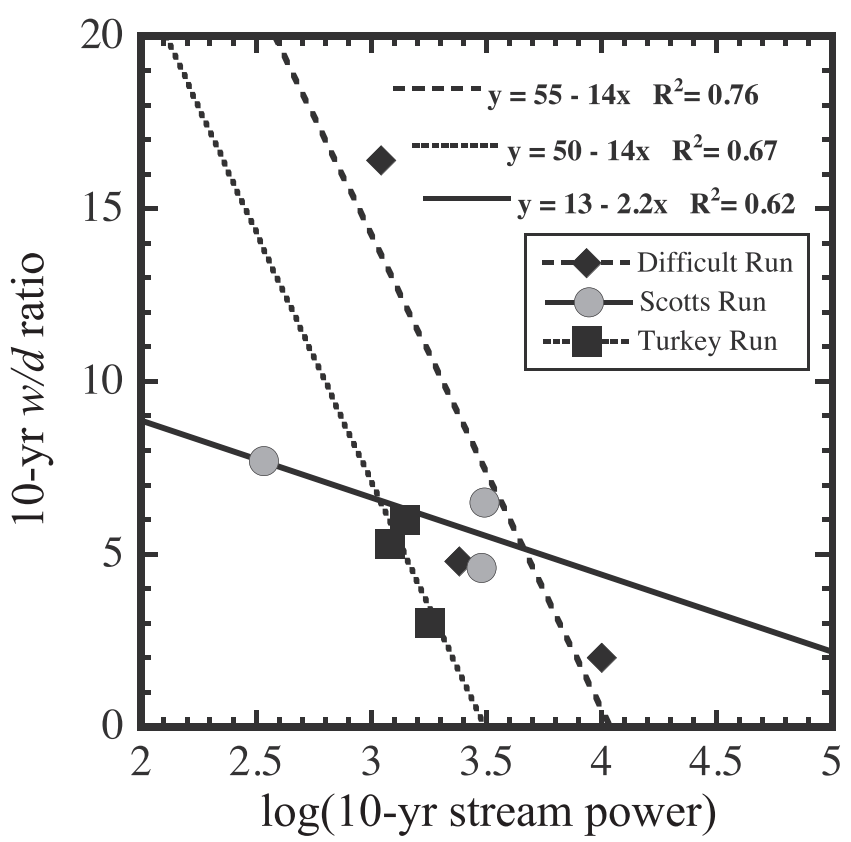

Figure 11. Relationships between stream power (surrogate for crosssection average erosion rate) and channel cross-section width/depth $(w / d)$ ratio, both calculated for the estimated 10-year flow. In all three channels, the $w / d$ ratio becomes smaller at higher values of stream power. However, the number of cross-sections measured is too low to draw statistically significant conclusions.

we observed that all measured sites also exhibited fractures $<2 \mathrm{~cm}$ in length and/or evidence of granular disintegration, although these were not quantified. Hence, we focus here on physical weathering processes, although chemical weathering processes likely play a role. Virtually all physical weathering processes should serve to increase rock erodibility by creating new fracture planes along which bedrock can be plucked or easily abraded, leading to lower rock strength, greater surface roughness, and greater crack density. For portions of the channel that are not regularly inundated, mechanical weathering, by increasing porosity and permeability, will result in a positive feedback whereby both physical and chemical weathering will be further enhanced by increased moisture content and by mechanical weakening. With our dataset, we cannot differentiate the contribution from specific physical weathering processes to observed cracking density at any given location (e.g. Eppes et al., 2016) or measure how physical 

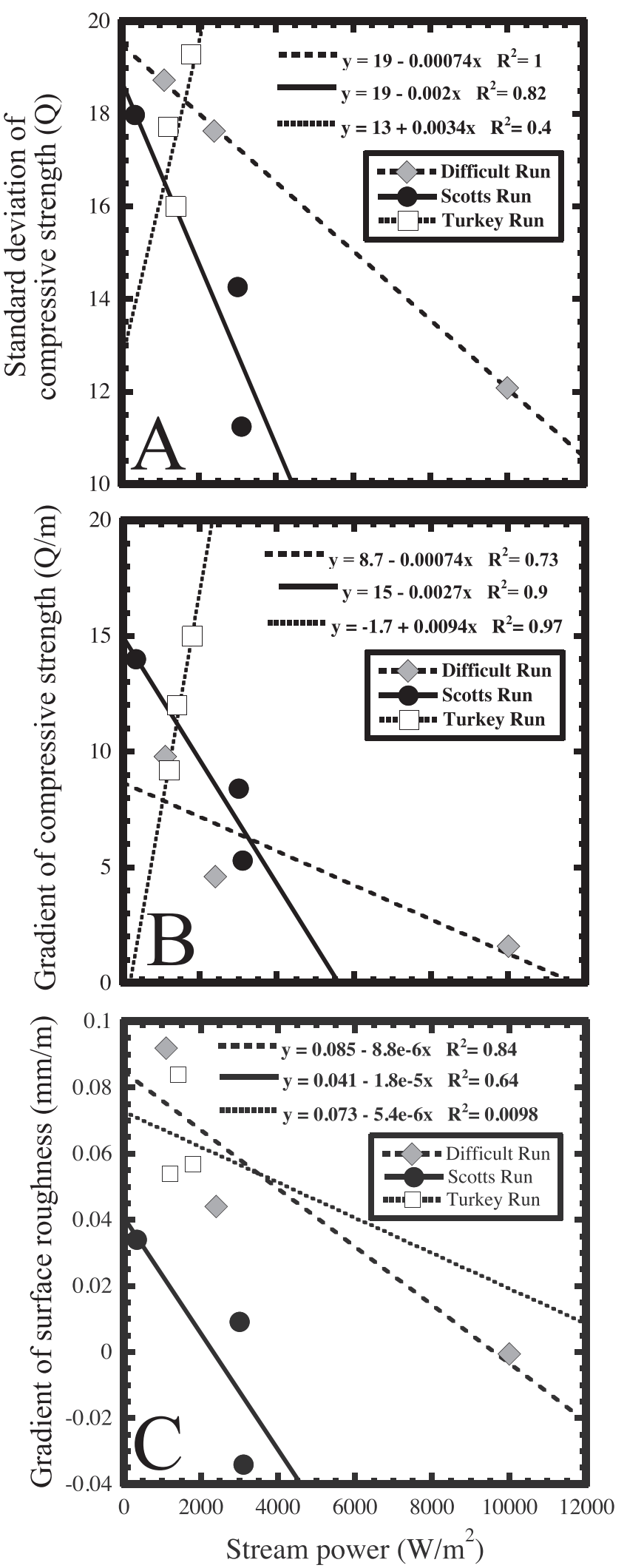

Figure 12. Comparison of stream power (surrogate for cross-section average erosion rate) with (A) standard deviation of compressive strength, (B) gradient of compressive strength and (C) gradient of surface roughness in each cross-section. Gradients are taken from the linear fits in Figures 5 and 6 for compressive strength and roughness, respectively. All three show that rock erodibility is more variable at lower stream power values on Difficult Run and Scott Run, while the lack of variability in stream power along Turkey Run precludes analysis of those data. However, the number of cross-sections measured is too low to draw statistically significant conclusions. weathering rates may change through time (Mushkin et al., 2014). Based on the climate conditions of the field site and past work on mechanical weathering processes in similar environments, however, it is likely that conditions are suitable for cracking or granular disintegration by thermal stress (e.g. Eppes et al., 2016), lichen growth or other biophysical processes (e.g. Lee and Parsons, 1999), ice segregation (e.g. Hales and Roering, 2007), and/or biotite expansion (e.g. Isherwood and Street, 1976). All of these likely contribute to mechanical weathering of the channels that we observed.

Our observations are consistent with previous studies that invoke weathering as an important mechanism for altering erodibility in bedrock channels (e.g. Howard, 1994; Whipple, 2004). Several field and laboratory studies note an increase of rock erodibility related to weathering of the rock surface in channels (e.g. Sklar and Dietrich, 2001; Montgomery, 2004; Stock et al., 2005; Johnson and Finnegan, 2015; Small et al., 2015; Murphy et al., 2016). Hence, we interpret our weathering proxies as indicative of rock erodibility in the sampled cross-sections. Further, the specific pattern of increasing degree of weathering and rock erodibility with height above the thalweg in our study is similar to other observations of rock erodibility in bedrock channels (Montgomery, 2004; Stock et al., 2005; Johnson and Finnegan, 2015; Small et al., 2015). Johnson and Finnegan (2015), Montgomery (2004), and Collins et al. (2016) present particularly dramatic examples of differential weathering across channels caused by wetting and drying cycles that are more frequent and thus more effective along the channel margins relative to the thalweg. The abrasion mill experiments of Small et al. (2015) document that erodibility varies significantly within channel cross-sections, with erodibility on the channel margins consistently greater, by up to an order-of-magnitude, than rock in the thalweg in the sampled sandstone and basaltfloored channels. The experiments of Sklar and Dietrich (2001) show that rock surfaces with evidence of weathering are significantly more erodible than fresh rocks of the same type, although we note that not all of their samples were collected in bedrock channels.

The erodibility pattern we observe supports the results of numerical simulations of bedrock-floored channel crosssection evolution that incorporate a weathering algorithm (Hancock et al., 2011). Similar to the erodibility pattern in our study site, the model predicts that differential weathering within channel cross-sections leads to a progressively greater degree of weathering and erodibility with increasing height above the thalweg. In the model, the increase in erodibility with height in the channel is related to decreasing inundation frequency with height. Bedrock near the channel thalweg weathers, but frequent inundation strips weathered material, preventing significant accumulation of weathering. With increasing height above the thalweg, inundation frequency decreases and erosion events are less frequent, allowing more time for weathering to weaken the rock (Hancock et al., 2011). These model results provide a viable mechanism to explain the observed increase in weathering accumulation with height in our sampled cross-sections. Variability in biological, chemical, or mechanical weathering rates along the channel cross-section is an alternative to differential inundation frequency as an explanation for the trends we observe. However, such a relationship is not straightforward. For example, consistent inundation and shading in the channel may insulate rock near the thalweg from temperature cycling, leading to less weathering by thermal stress. Alternatively, more efficient erosion at the thalweg may result in faster weathering rates there because fresh rock is exposed. We consider the mechanism of differential inundation frequency to be the 
simplest and most likely explanation for the trends we observe, but it is plausible that spatial and temporal variability in weathering processes plays an additional role.

\section{Cross-channel erodibility, stream power, and channel geometry}

Our data supports the hypothesis that erosion rate and weathering interact to set the pattern of erodibility across channels and, in turn, influence channel geometry. We consider the relationships between stream power, erodibility, and channel geometry in our study cross-sections (Figures 11 and 12). Because the sampled cross-sections on each individual tributary have similar lithology, discharge, and regional climatic conditions, we suggest that the erosion rate in each cross-section plays a key role in controlling the observed differences in erodibility and cross-section geometry. While there are no direct measurements of erosion rates on the three tributaries sampled, stream power varies significantly between cross-sections on both Difficult Run and Scotts Run (Table I). The stream power variability is in large part a reflection of differences in channel slope related to a marked profile convexity, starting at an elevation of $\sim 50 \mathrm{~m}$, within each channel profile (Figure 2). The convexities were likely spawned by the passage of a knickpoint (Great Falls) migrating past each tributary confluence with the Potomac River (Bierman et al., 2004) and have migrated upstream to their present locations (cross-sections DR-M and SR-M). Above the tributary knickpoints, channel incision rates are likely slow, as long-term regional erosion rates within the Piedmont province near Great Falls are up to $\sim 0.02 \mathrm{~m} / \mathrm{kyr}$ averaged over the last several million years (Pavich, 1989). In contrast, average incision rates in this reach of the Potomac River are on the order of $0.1 \mathrm{~m} / \mathrm{kyr}$ over the past $50 \mathrm{kyr}$ (Bierman et al., 2004; Reusser et al., 2004; Bierman, 2015) and may have accelerated up to $0.8 \mathrm{~m} /$ kyr as the Great Falls knickpoint migrated upstream (Reusser et al., 2004). As we have sampled cross-sections located above, within, and below the tributary knickpoints on each tributary, we infer that erosion rates vary by nearly an order of magnitude between cross-sections. Lacking actual erosion rates, however, we use unit stream power as a proxy for erosion rate.

We consider the standard deviation of compressive strength (Figure 12A) to be an indicator of the variability in rock strength produced by weathering within the channel cross-section. In general, Figure $12 \mathrm{~A}$ suggests a relationship between stream power and standard deviation in Difficult Run and Scotts Run in which standard deviation decreases with increasing unit stream power (Figure 11). Assuming stream power is a reasonable proxy for erosion rate, we conclude that increasing erosion rate decreases the variability in erodibility, because more frequent erosion events prevent the accumulation of weathering effects within the entire channel.

We now assess the rate of change in compressive strength and surface roughness with height in each cross-section (Figures 12B and $12 \mathrm{C}$ ), which we assume to be an indicator of the effectiveness of weathering relative to erosion with increasing height in the cross-section. In general, the overall rate of change of both compressive strength and surface roughness decreases as stream power increases in Difficult Run and Scotts Run (Figures 12B and 12C). Though the relationships in Figure 12 are not statistically significant because of our low sample size, these results suggest that channels with higher erosion rates maintain greater rock strength throughout the channel crosssection. While Murphy et al. (2016) found a positive relationship between incision rate and compressive strength along channel longitudinal profiles, our results highlight that stronger rock is found at all points in rapidly eroding crosssections relative to slowly eroding cross-sections. We note that Turkey Run does not show relationships similar to those discussed earlier for Difficult Run and Scotts Run, as the range of stream power within the Turkey Run cross-sections is low compared to the other two channels (Figures 11 and 12).

Observed channel $w / d$ ratios are also generally negatively correlated to stream power (Figure 11), with the $w / d$ ratio in Difficult Run strongly and negatively correlated to stream power, although Scotts Run and Turkey Run have similar but weaker relationships (Figure 11). These data suggest that increasing erosion rates and the concomitant decrease in rock erodibility at points high on the channel margin lead to lower $w / d$ ratios. This result provides evidence for a dynamic feedback in which incision rates influence the pattern of rock strength within channels, which in turn influences channel form and erosion. One alternative, or possibly complementary, hypothesis for lower $w / d$ ratios at higher erosion rates is that increased bedload transport capacity can focus erosion by saltating bedload at the thalweg relative to the banks (e.g. Lamb et al., 2015). While we do not have the data to distinguish between these two processes, strong rock on the channel banks would still be more resistant to clear-water erosion (e.g. plucking) and abrasion by suspended load than the weathered banks found in low erosion rate cross-sections. An important implication of this conclusion is that variables such as microclimate or lithologic heterogeneity that control weathering rates will influence not only the minimum and maximum rock erodibility in a channel, but also the range of erodibility between the thalweg and the channel margins. Ultimately, rock strength is likely a dynamic channel variable whose magnitude and variability are set by the competition between rock removal by erosion processes and the preservation of weathered rock within the channel.

The linkages we observe between channel $w / d$ ratio, weathering, and erosion rate are consistent with predictions derived from several numerical simulations of bedrock-floored channel cross-section evolution. The modeling results of Hancock et al. (2011) show a decrease in $w / d$ ratio and a reduction in the variability in erodibility as a channel transitions from moderate to high erosion rates when weathering is incorporated in the model. In contrast, $w / d$ ratios are static in simulations that do not include weathering of the channel even though width narrows as erosion rate increases from moderate to high erosion rates (Hancock et al., 2011), which is consistent with the predictions of similar models of detachment-limited (i.e. pure bedrock) channels (Hancock et al., 2011; Yanites and Tucker, 2010; Wobus et al., 2006). We conclude that it is the distribution of erodibility in the observed channels, driven by the erosion rate within each cross-section, that significantly influences each reach's channel geometry.

Additional support of our conclusions arises from considering the effects of sediment cover on bedrock channels. The bedrock cross-section simulations of Yanites and Tucker (2010) that incorporate sediment cover, but not weathering, produce cross-sections with nearly identical $w / d$ ratios to those presented in Hancock et al. (2011) that incorporate a rock weathering algorithm within channels, but without sediment. The field observations presented herein provide evidence that both sediment cover and spatially variable erodibility may play a role in channel width and $w / d$ ratio. In cross-sections where both the magnitude and variability of rock erodibility are high, channel width and $w / d$ ratios are greater at the $Q_{10}$ and $Q_{50}$ flows while channel gradient is lower, relative to cross-sections with less erodible bedrock (Figure 12, Table I). In addition, 
qualitative observations at the sampled cross-sections suggest that the fraction of sediment cover increases as unit stream power decreases, similar to the relationships we hypothesize exist between width, $w / d$ ratio, rock erodibility, and unit stream power. At the extreme, we would expect that bedrock crosssections that are eroding sufficiently slowly would weather to a nearly uniform high erodibility (Hancock et al., 2011). Uniformly erodible rock, coupled with burial by sediment, may lead to a transition to transport-limited conditions in which sediment flux and size control channel geometry and slope (e.g. Yanites and Tucker, 2010). Although not sampled, we observed such a cross-section on Difficult Run $\sim 250 \mathrm{~m}$ upstream of DR- $U$, where the channel transitions to a wide floodplain and low gradient with near complete sediment cover and where exposed bedrock is saprolitized (Supporting Information Figure S2).

\section{Implications for channel geometry and gradient}

Lacking a theoretical basis for downstream variations in bedrock channel width, geomorphologists have frequently adopted scaling relationships based on hydraulic geometry of alluvial rivers (Leopold and Maddock, 1953). Though there is good empirical support for discharge-based scaling where width $(w)$ in bedrock channels generally scales with discharge $(Q)$ by the relationship $w \propto Q^{b}$, where $b \sim 0.4-0.55$ (e.g. Montgomery and Gran, 2001; Whipple, 2004; Wobus et al., 2006; Finnegan et al., 2007; Turowski et al., 2008; Wohl and David, 2008), many examples exist of bedrock channels narrowing downstream due to baselevel perturbations (e.g. this study) or other factors. Although a relationship $w \propto Q^{0.5}$ is widely used in scaling relationships in models of longitudinal profile evolution, the datasets comparing width and discharge tend to be quite noisy (e.g. Figure 1 in Wohl and David, 2008). The noise is due to the many factors that contribute to the variability in channel width found along and between rivers in these field studies, including differences in incision rate, bedrock characteristics, precipitation rate, and sediment supply (e.g. Montgomery and Gran, 2001; Duvall et al., 2004; Turowski et al., 2008, Wohl and David, 2008; Han et al., 2014). Unlike for channel width, Wohl and David (2008) find no significant pattern of $w / d$ ratio as a function of $Q$ or drainage area, $A$, in contrast to predictions that $w / d$ should be constant along channels or scale with $Q$ and $A$ (e.g. Wobus et al., 2006). The modeling results of Hancock et al. (2011) coupled with the field data presented herein suggest that weathering, and more precisely the pattern of accumulated weathering within channel cross-sections, may be an important source of variability in both channel width and $w / d$ ratio. Our results suggest that the pattern of erodibility within channel cross-sections generated by differential accumulation of weathering is an additional degree of freedom in adjustment of channel width and $w / d$ ratio. Further, because incision rate, lithology, precipitation, and sediment supply influence in-channel weathering rates and processes, bedrock weathering likely works in concert with these variables to influence channel geometry for any given reach.

\section{Conclusions}

Bedrock erodibility, as inferred from compressive strength, surface roughness, and crack density measurements, exhibits significant spatial variability within cross-sections on three tributaries to the Potomac River. Eight of nine channel crosssections exhibit statistically significantly higher rock compressive strength at the measurement height nearest the thalweg than at the measurement highest on the bank. Rock surface roughness and crack density are generally higher at sample locations on the channel banks than at near-thalweg sample locations. Further, we find compelling evidence that the distribution of rock erodibility in cross-sections (i.e. the magnitude of the difference between erodibility at the thalweg and on the channel margins) is strongly controlled by the crosssection erosion rate. We conclude from these data that (1) bedrock erodibility is greater along the channel margins where inundation is less frequent, as weathering effects accumulate without frequent stripping by erosion, and (2) cross-section stream power, used as a proxy for erosion rate, can explain much of the variation in differences between near thalweg and channel margin erodibility in the nine cross-sections. We conclude that the increase in erodibility with height is related to the decreasing frequency of erosive events with increasing height in channel cross-sections, leading to more accumulation of weathering, and therefore greater rock erodibility, on the channel margins relative to the thalweg. Our crack density data demonstrate that a large portion of the observed weathering is mechanical, rather than chemical weathering as observed in Hawaii by Murphy et al. (2016).

Our observations of high values for standard deviation and range of compressive strength measurements in many crosssections (DR- $U$, DR-L, SR- $U, T R-U, T R-L$ ) indicate that there is no single value of rock erodibility that characterizes the entire channel cross-section. The noisy yet broadly consistent inverse relationship between the standard deviation of compressive strength and unit stream power is evidence that the patterns in erodibility that we observe result from the interplay between cross-section erosion rate and degree of weathering, driven by the accumulation of weathering effects.

We show evidence that the erosion rate, in concert with the differential degree of weathering between the thalweg and channel margins, may set the cross-sectional channel geometry. These findings imply that factors that influence weathering rates will work in concert with erosion to set the distribution of rock erodibility and therefore control channel geometry in any given channel reach. For a given erosion rate, a cross-section whose margins have a greater accumulation of weathering than in the thalweg will have a higher $w / d$ ratio and a lower channel gradient than a cross-section with uniform erodibility (Hancock et al., 2011). Our field results support the existence of such a relationship, as the wider, shallower crosssections (e.g. DR-U, SR-U) tend to have more significant accumulation of weathering effects on the channel margins than the deep, narrow cross-sections (e.g. DR-M, SR-M). Greater weathering accumulation on the channel banks relative to the thalweg may be an important mechanism in allowing cross-sections to lower uniformly in space despite higher concentrations of erosive power near the thalweg. This study provides novel, quantitative field evidence that weathering is a prime contributor to the significant variability found in bedrock channel geometries and gradients.

Acknowledgements - This work was supported by NSF Geomorphology and Land Use Dynamics EAR 0922026 (to GSH and EES), a William and Mary Roy R. Charles Center student research grant (to CMS), and a National Defense Science and Engineering Graduate Fellowship (to CMS). The authors thank Brendan Murphy, Lauren Lamp, Matt Sparacino, and Max Cunningham for valuable discussions, and Hanna Bartram, Suzanne Ching, Sofia DiBari, Jamie Gehman, Connor Kee, Betty Joyce Nash, Steven Rachide, Sarah Sanford, Aiken Small, Emily Smith, and Kyle Stark for field assistance. Reviews by Dan Scott, one anonymous reviewer, and associate editor Ellen Wohl greatly improved this manuscript. 


\section{References}

Aldred J, Eppes MC, Aquino K, Deal R, Garbini J, Swami S, Tuttle A, Xanthos G. 2015. The influence of solar-induced thermal stresses on the mechanical weathering of rocks in humid mid-latitudes. Earth Surface Processes and Landforms 41(5): 603-614.

Austin SH, Krstolic JL, Wiegand U. 2011. Peak Flow Characteristics of Virginia Streams, USGS Scientific Investigations Report 2011-5144. US Geological Survey: Reston, VA.

Aydin A, Basu A. 2005. The Schmidt hammer in rock material characterization. Engineering Geology 81: 1-14.

Berlin MM, Anderson RS. 2009. Steepened channels upstream of knickpoints: controls on relict landscape response. Journal of Geophysical Research: 114: F03018.

Bierman P. 2015. The incision history of the Great Falls of the Potomac River - the Kirk Bryan field trip. In Tripping from the Fall Line: Field Excursions for the GSA Annual Meeting, Baltimore, 2015, Brezinski DK, Halka JP, Ortt RA Jr. (eds). Geological Society of America Field Guide 40: 1-10.

Bierman P, Zen E, Pavich M, Reusser L. 2004. The incision history of a passive margin river, the Potomac near Great Falls. In Geology of the National Capital Region - Field Trip Guidebook, Southworth S, Burton W (eds), US Geological Survey Circular 1264. Reston, VA: US Geological Survey.

Birkeland P. 1999. Soils and Geomorphology, third edn. Oxford: Oxford University Press.

Blackwelder E. 1931. Pleistocene glaciations of the Sierra Nevada and Basin Ranges. Geological Society of America Bulletin 42: 865-922.

Burbank DW, Leland J, Fielding E, Anderson RS, Brozovic N, Reid MR, Duncan C. 1996. Bedrock incision, rock uplift and threshold hillslopes in the northwestern Himalayas. Nature 379: 505-510.

Canny J. 1986. A computational approach to edge detection. IEEE Transactions on Pattern Analysis and Machine Intelligence PAMI-8: 679-698.

Chow VT. 1959. Open-channel Hydraulics. McGraw-Hill: New York; 680.

Collins BD, Montgomery DR, Schanz SA, Larsen IJ. 2016. Rates and mechanisms of bedrock incision and strath terrace formation in a forested catchment, Cascade Range, Washington. Geological Society of America Bulletin 128: 926-943.

Drake AA, Froelich AJ. 1997. Geologic Map of the Falls Church Quadrangle, Fairfax and Arlington Counties and the City of Falls Church, Virginia, and Montgomery County, Maryland, Geologic Quadrangle Map. Reston, VA: US Geological Survey.

Duvall A, Kirby E, Burbank D. 2004. Tectonic and lithologic controls on bedrock channel profiles and processes in coastal California. Journal of Geophysical Research 109: F03002.

Eppes MC, McFadden L, Wegmann K, Scuderi L. 2010. Cracks in desert pavement rocks: further insights into mechanical weathering by directional solar heating. Geomorphology 123: 97-108.

Eppes MC, Magi B, Hallet B, Delmelle E, Mackenzie-Helnwein P, Warren K, Swami S. 2016. Deciphering the role of solar-induced thermal stresses in rock weathering. Geological Society of America Bulletin 128(9-10): 1315-1338.

Ericson K. 2004. Geomorphological surfaces of different age and origin in granite landscapes: an evaluation of the Schmidt hammer test. Earth Surface Processes and Landforms 29: 495-509.

Finnegan NJ, Sklar L, Fuller TK. 2007. Interplay of sediment supply, river incision, and channel morphology revealed by the transent evolution of an experimental bedrock channel. Journal of Geophysical Research: Earth Surface 112: F3.

Gómez-Pujol L, Fornós JJ, Swantesson JOH. 2006. Rock surface millimeter-scale roughness and weathering of supratidal Mallorcan carbonate coasts (Balearic Islands). Earth Surface Processes and Landforms 31: 1792-1801.

Goode JR, Wohl E. 2010. Substrate controls on the longitudinal profile of bedrock channels; implications for reach-scale roughness. Journal of Geophysical Research 115: F03018.

Goudie AS. 2006. The Schmidt hammer in geomorphological research. Progress in Physical Geography 30: 703-718.

Gupta AS, Rao KS. 2000. Weathering effects on the strength and deformational behavior of crystalline rocks under uniaxial compression state. Engineering Geology 56(3-4): 257-274.
Hales TC, Roering JJ. 2007. Climatic controls on frost cracking and implications for the evolution of bedrock landscapes. Journal of Geophysical Research 112: F02033.

Han J, Gasparini NM, Johnson JPL, Murphy BP. 2014. Modeling the influence of rainfall gradients on discharge, bedrock erodibility, and river profile evolution, with application to the Big Island, Hawai'i. Journal of Geophysical Research: Earth Surface 119: 1418-1440.

Hancock GS, Anderson RS, Whipple KX. 1998. Beyond power: bedrock river incision process and form. In Rivers over Rock, Tinkler KJ, Wohl EE (eds), American Geophysical Union Geophysical Monograph 107. American Geophysical Union: Washington, DC; 35-60.

Hancock GS, Small EE, Wobus C. 2011. Modeling the effects of weathering on bedrock-floored channel geometry. Journal of Geophysical Research 116: F03018.

Haviv I, Enzel Y, Whipple KX, Zilberman E, Stone J, Matmon A, Fifield LK. 2006. Amplified erosion above waterfalls and oversteepened bedrock reaches. Journal of Geophysical Research: 111.

Hobley DEJ, Sinclair HD, Cowie PA. 2010. Processes, rates, and time scales of fluvial response in an ancient postglacial landscape of the northwest Indian Himalaya. Geological Society of America Bulletin 122: 1569-1584.

Howard AD. 1994. A detachment-limited model of drainage basin evolution. Water Resources Research 30: 2261-2285.

Howard AD. 1998. Long profile development of bedrock channels: interaction of weathering, mass wasting, bed erosion, and sediment transport. In Rivers over Rock, Tinkler KJ, Wohl EE (eds), American Geophysical Union Geophysical Monograph 107. American Geophysical Union: Washington, DC; 297-319.

Howard AD, Kerby G. 1983. Channel changes in badlands. Geological Society of America Bulletin 94: 739-752.

Huda SA, Small EE. 2014. Modeling the effects of bed topography on fluvial bedrock erosion by saltating bed load. Journal of Geophysical Research: Earth Surface 119(6): 1222-1239.

Isherwood D, Street A. 1976. Biotite-induced grussification of the Boulder Creek Granodiorite, Boulder County, Colorado. Geological Society of America Bulletin 87(3): 366-370.

Johnson KN, Finnegan NJ. 2015. A lithologic control on active meandering in bedrock channels. Geological Society of America Bulletin 127: 1766-1776.

Lague D. 2014. The stream power river incision model: evidence, theory and beyond. Earth Surface Processes and Landforms 39: 38-61.

Lamb MP, Finnegan NJ, Scheingross JS, Sklar LS. 2015. New insights into the mechanics of fluvial bedrock erosion through flume experiments and theory. Geomorphology 244: 33-55.

Lee M, Parsons I. 1999. Biomechanical and biochemical weathering of lichen-encrusted granite: textural controls on organic-mineral interactions and deposition of silica-rich layers. Chemical Geology 161(4): 385-397.

Leopold LB, Maddock T. 1953. The Hydraulic Geometry of Stream Channels and Some Physiographic Implications, USGS Professional Paper 252. Reston, VA: US Geological Survey.

McCarroll D. 1991. The Schmidt hammer, weathering and rock surface roughness. Earth Surface Processes and Landforms 16: 477-480.

McCarroll D. 1997. A template for calculating rock surface roughness. Earth Surface Processes and Landform 22: 1229-1230.

McCarroll D, Nesje A. 1996. Rock surface roughness as an indicator of degree of rock surface weathering. Earth Surface Processes and Landforms 21: 963-977.

Montgomery DR. 2004. Observations on the role of lithology in strath terrace formation and bedrock channel width. American Journal of Science 304: 454-476.

Montgomery DR, Gran KB. 2001. Downstream variations in the width of bedrock channels. Water Resources Research 37: 1841-1846.

Murphy BP, Johnson JPL, Gasparini NM, Sklar LS. 2016. Chemical weathering as a mechanism for the climatic control of bedrock river incision. Nature 532: 223-226.

Mushkin A, Sagy A, Trabelci E, Amit R, Porat N. 2014. Measuring the time and scale-dependency of subaerial rock weathering rates over geologic time scales with ground-based lidar. Geology 42: 1063-1066. 
Niedzielski T, Migon P, Placek A. 2009. A minimum sample size required from Schmidt hammer measurements. Earth Surface Processes and Landforms 34: 1713-1725.

Pavich MJ. 1989. Regolith residence time and the concept of surface age of the Piedmont "Peneplain.". Geomorphology 2(1-3): 181-196. Reusser LJ, Bierman PR, Pavich MJ, Zen E, Larsen J, Finkel R. 2004. Rapid late Pleistocene incision of Atlantic Passive-Margin river gorges. Science 305: 499-502.

Selby MJ. 1980. A rock mass strength classification for geomorphic purposes: with tests from Antarctica and New Zealand. Zeitschrift für Geomorphologie 24: 31-51.

Sklar L, Dietrich W. 2001. Sediment and rock strength controls on river incision into bedrock. Geology 29: 1087-1090.

Small EE, Blom T, Hancock GS, Hynek BM, Wobus CW. 2015. Variability of rock erodibility in bedrock-floored stream channels based on abrasion mill experiments. Journal of Geophysical Research: Earth Surface 120: 1455-1469.

Sousa LMO, del Rio LMS, Calleja L, de Argandoña VGR, Ray AR. 2005. Influence of microfractures and porosity on the physic-mechanical properties and weathering of ornamental granites. Engineering Geology 77(1-2): 153-168.

Spears DA, Taylor RK. 1972. The influence of weathering on the composition and engineering properties of in situ coal measures rocks. International Journal of Rock Mechanics and Mining Sciences 9: 729-756.

Stark CP. 2006. A self-regulating model of bedrock river channel geometry. Geophysical Research Letters 33(4): L04402.

Stock JD, Montgomery DR, Collins BD, Dietrich WE, Sklar L. 2005. Field measurements of incision rates following bedrock exposure: implications for process controls on the long profiles of valleys cut by rivers and debris flows. Geological Society of America Bulletin 117: 174-194.

Sumner P, Nel W. 2002. The effect of rock moisture on Schmidt hammer rebound: tests on rock samples from Marion Island and South Africa. Earth Surface Processes and Landforms 27: 1137-1142.

Tucker GT, Whipple KX. 2002. Topographic outcomes predicted by stream erosion models: sensitivity analysis and intermodel comparison. Journal of Geophysical Research: Solid Earth 107(B9): 2179 .
Tugrul A. 2004. The effect of weathering on pore geometry and compressive strength of selected rock types from Turkey. Engineering Geology 75: 215-227.

Turowski JM, Hovius N, Wilson A, Horng MJ. 2008. Hydraulic geometry, river sediment and the definition of bedrock channels. Geomorphology 99: 26-38.

Turowski JM, Lague D, Hovius N. 2009. Response of bedrock channel width to tectonic forcing: insights from a numerical model, theoretical considerations, and comparison with field data. Journal of Geophysical Research 114: F03016.

Whipple KX. 2004. Bedrock rivers and the geomorphology of active orogens. Annual Review of Earth and Planetary Sciences 32: 151-185.

Whipple KX, Tucker GE. 1999. Dynamics of the stream-power river incision model: implications for height limits of mountain ranges, landscape response timescales, and research needs. Journal of Geophysical Research 104: 17661-17674.

Whipple KX, Hancock GS, Anderson RS. 2000. River incision into bedrock: mechanics and relative efficacy of plucking, abrasion, and cavitation. Geological Society of America Bulletin 112: 490-503.

Wobus CW, Tucker GE, Anderson RS. 2006. Self-formed bedrock channels. Geophysical Research Letters: 33: L18408.

Wobus CW, Kean JW, Tucker GE, Anderson RS. 2008. Modeling the evolution of channel shape: Balancing computational efficiency with hydraulic fidelity. Journal of Geophysical Research 113: F02004.

Wohl EE. 1993. Bedrock channel incision along Piccaninny Creek, Australia. The Journal of Geology 101(6): 749-761.

Wohl EE, Achyuthan H. 2002. Substrate influences on incised-channel morphology. Journal of Geology 110: 115-120.

Wohl EE, David GCL. 2008. Consistency of scaling relations among bedrock and alluvial channels. Journal of Geophysical Research 113: F04013.

Yanites BJ, Tucker GE. 2010. Controls and limits on bedrock channel geometry. Journal of Geophysical Research: Earth Surface 115: F04019.

\section{Supporting Information}

Additional Supporting Information may be found online in the supporting information tab for this article. 